\title{
Advances of Yb:CALGO Laser Crystals
}

\author{
Hao Wang ${ }^{1,2} \mathbb{D}^{\text {, Jing Pan }}{ }^{1,2}$, Yuan Meng ${ }^{1,2} \mathbb{C}$, Qiang Liu ${ }^{1,2, *}$ and Yijie Shen ${ }^{3, *}$ \\ 1 Key Laboratory of Photonic Control Technology, Tsinghua University, Ministry of Education, \\ Beijing 100084, China; h-wang20@mails.tsinghua.edu.cn (H.W.); pj18@mails.tsinghua.edu.cn (J.P.); \\ mengy16@mails.tsinghua.edu.cn (Y.M.) \\ 2 State Key Laboratory of Precision Measurement Technology and Instruments, \\ Department of Precision Instrument, Tsinghua University, Beijing 100084, China \\ 3 Optoelectronics Research Centre, University of Southampton, Southampton SO17 1BJ, UK \\ * Correspondence: qiangliu@tsinghua.edu.cn (Q.L.); y.shen@soton.ac.uk (Y.S.)
}

Citation: Wang, H.; Pan, J.; Meng, Y.; Liu, Q.; Shen, Y. Advances of Yb:CALGO Laser Crystals. Crystals 2021, 11, 1131. https://doi.org/ $10.3390 /$ cryst11091131

Academic Editors: Jingsong Li, Qingli Zhang and Zhirong Zhang

Received: 1 September 2021

Accepted: 15 September 2021

Published: 17 September 2021

Publisher's Note: MDPI stays neutral with regard to jurisdictional claims in published maps and institutional affiliations.

Copyright: (c) 2021 by the authors. Licensee MDPI, Basel, Switzerland. This article is an open access article distributed under the terms and conditions of the Creative Commons Attribution (CC BY) license (https:// creativecommons.org/licenses/by/ $4.0 /)$.

\begin{abstract}
Yb}: \mathrm{CaGdAlO}_{4}$, or $\mathrm{Yb}: \mathrm{CALGO}$, a new laser crystal, has been attracting increasing attention recently in a myriad of laser technologies. This crystal features salient thermal, spectroscopic and mechanical properties, which enable highly efficient and safe generation of continuous-wave radiations and ultrafast pulses with ever short durations. More specifically, its remarkable thermaloptic property and its high conversion efficiency allow high-power operation. Its high nonlinear coefficient facilitates study of optimized mode locking lasers. Besides, its ultrabroad and flat-top emission band benefits the generation of complex structured light with outstanding tunability. In this paper, we review the recent advances in the study of $\mathrm{Yb}: \mathrm{CALGO}$, covering its physical properties as well as its growing applications in various fields and prospect for future development.
\end{abstract}

Keywords: Yb:CALGO; solid-state laser; tunable laser; ultrafast optics; structured light

\section{Introduction}

Laser technologies have been booming with important breakthroughs in both theoretical and experimental aspects [1-4], propelling the advances of diverse fields including ultrafast optoelectronics [5,6], laser fabrication [7,8] and laser therapy $[9,10]$. The gain medium is the kernel of a laser, which fundamentally determines the output characteristics including pulse energy, power and output spectrum. In solid-state lasers, the gain media are crystals or glasses doped with various metal ions, among which there are many famous ones, such as Nd:YAG [11-13], Cr:YAG [14,15], Nd:YVO 4 [16,17], to name a few. To meet the ever-increasing demands for superior laser performance, the quest for new gain media never wanes. One of them, $\mathrm{Yb}: \mathrm{CaGdAlO}_{4}$ [18], abbreviated as $\mathrm{Yb}: \mathrm{CALGO}$ (or Yb:CGA), has enjoyed a great success with remarkable results in high efficiency lasers, low quantum defect lasers, broad wavelength-tunability lasers, narrow pulse width lasers, high peak power lasers, structured beam lasers, etc.

The reason why $\mathrm{Yb}: \mathrm{CALGO}$ stands out can be attributed to its unique composition. The energy transition of the ytterbium ion $\left(\mathrm{Yb}^{3+}\right)$ occurs at ${ }^{2} \mathrm{~F}_{5 / 2} \rightarrow{ }^{2} \mathrm{~F}_{7 / 2}$. This neat energylevel scheme avoids the emergence of parasitic excited state absorption and up-conversion processes, thus giving low heat load and high quantum efficiency [19,20]. Meanwhile, the absorption spectra of $\mathrm{Yb}$-doped media peak at $\sim 979 \mathrm{~nm}$, which can be well pumped by commercially available InGaAs laser diode (one condition that can never be ignored for favorable lasers) [21]. Hence, many nontrivial experimental results of $\mathrm{Yb}$-doped lasers came out over the past decades [22-25]. Notwithstanding the foregoing, researchers found that the quantum defect near zero regarding $\mathrm{Yb}^{3+}$ ions can differ significantly from host to host [26]. Additionally, tetragonal rare-earth calcium aluminate $\mathrm{CaGdAlO}_{4} / \mathrm{CALGO}$ is a noteworthy member because of its disordered structure [27]. So, intuitively, the combination of $\mathrm{Yb}^{3+}$ ions and CALGO may be of great promise. Indeed, in 2005, Petit et al. first reported the result of laser emission using Yb:CALGO and developed its crystal 
growth, thermal, optical and laser properties [18]. Except for the obtained 40\% slope efficiency, 3.5\% quantum defect and $\sim 600 \mathrm{~mW}$ output at $1016 \mathrm{~nm}$ when using $\sim 1.8 \mathrm{~W}$ pump and a 2 at. \% Yb:CALGO sample, its broad and smooth emission spectrum with a peculiarly flat plateau between $990 \mathrm{~nm}$ and $1050 \mathrm{~nm}$ and the advantages of easily growing, cutting and polishing enlighten its future and lead to soaring research attention on itself over the past 15 years.

In this work, we review the recent advances in study of Yb:CALGO. We first introduce the important physical properties of $\mathrm{Yb}: \mathrm{CALGO}$, which are fundamental to understand various applications of the gain medium. Then, we discuss the recent advances in different laser schemes. Results are analyzed and compared, covering high efficiency lasers, low quantum defect lasers, broad wavelength-tunability lasers, narrow pulse width lasers, high peak power lasers and structured beam lasers. In the last chapter, we prospect for more potential applications of $\mathrm{Yb}: \mathrm{CALGO}$, especially in both ultrafast photonics and generation of versatile high-tunability structured light.

\section{Properties}

In this chapter, we summarize fundamental properties of $\mathrm{Yb}$ :CALGO, from the synthesis method, atomic structure to physical parameters. We also highlight the outstanding physical properties by comparison with other common Yb-doped crystals.

\subsection{Crystal Preparation and Structure}

The Yb:CALGO crystal is typically grown by the Czochralski (CZ) technique [18,28]. In brief, $\mathrm{Yb}_{2} \mathrm{O}_{3}, \mathrm{CaCO}_{3}, \mathrm{Gd}_{2} \mathrm{O}_{3}$ and $\mathrm{Al}_{2} \mathrm{O}_{3}$ powders are mixed at stoichiometric portions as raw materials ingredients based on the formula of $\mathrm{CaGd}_{0.92} \mathrm{Yb}_{0.08} \mathrm{AlO}_{4}$ (ratio of ref. [28]). Then, they are turned into pieces under high pressure (around $300 \mathrm{MPa}$ ). In quick succession, those pieces are charged and sintered, and the reaction $\left(\mathrm{CaCO}_{3}+0.04 \mathrm{Yb}_{2} \mathrm{O}_{3}+\right.$ $0.46 \mathrm{Gd}_{2} \mathrm{O}_{3}+0.5 \mathrm{Al}_{2} \mathrm{O}_{3}=\mathrm{CaGd}_{0.92} \mathrm{Yb}_{0.08} \mathrm{AlO}_{4}+\mathrm{CO}_{2} \uparrow$ ) happens under high temperature (1200 ${ }^{\circ} \mathrm{C}$, for example). With a CALGO single crystal as the seed, the crystal can be pulled out of the melt properly as shown in the lower right of Figure 1a [29]. Note that it can look colorless or gradually changed from different manufacturers.

To further comprehend macroscopic properties of $\mathrm{Yb}: \mathrm{CALGO}$, one needs to go deeper about the microscopic structure of this anisotropic crystal shown in Figure 1a. The rareearth calcium aluminate $\mathrm{CaLnAlO}_{4}$ where $\mathrm{Ln}=\mathrm{Y}$, La $\ldots \mathrm{Gd} \ldots \mathrm{Lu}$, is a member of $\mathrm{ABCD}_{4}$ compounds with $\mathrm{K}_{2} \mathrm{NiF}_{4}$ structure, where $\mathrm{A}=\mathrm{Ca}$, $\mathrm{Sr}$ or $\mathrm{Ba}, \mathrm{B}=\mathrm{Gd}$ or some other rare-earth metals and $\mathrm{C}=\mathrm{Al}, \mathrm{Ga}$ or some transition metals. It has space group $\mathrm{I}_{4} / \mathrm{mmm}\left(\mathrm{D}_{4 \mathrm{~h}}{ }^{17}\right)$ and belongs to the tetragonal system. In a $\mathrm{K}_{2} \mathrm{NiF}_{4}$-type structure, the small $\mathrm{Al}$ atoms are in slightly distorted octahedral sites, which are stacked in layers perpendicular to the c-direction. The large divalent $\mathrm{Ca}$ and trivalent Gd ions occupy the same sites statistically with a nine-fold coordination [30]. Note that the difference between the atom radius values of $\mathrm{Ca}^{2+}$ and $\mathrm{Gd}^{3+}$ is pretty trivial (1.18 $\AA$ and $1.11 \AA$, respectively). Thus, a disordered occupation of their sites can be anticipated [31]. They have distorted $C_{4 v}$ symmetry [20] and quite high mechanical strength (Mohs hardness 6) [32]. Then, the dopant impurities $\mathrm{Yb}^{3+}$ are expected to substitute for both the $\mathrm{Ca}^{2+}$ and $\mathrm{Gd}^{3+}$ sites. In fact, this kind of substitution effect is utilized prevailingly to broaden the width of gain spectrum in laser science, considering that a normal rare-earth ion's gain spectral bandwidth is limited to several nanometers and its absorption cross-section is quite low [21]. For instance, in $\mathrm{Yb}: \mathrm{CaF}_{2}$, a media that is often used in broadly tunable, high-power and short pulse laser regimes [33], trivalent $\mathrm{Yb}$ ions displace divalent $\mathrm{Ca}$ ions, which increases the structural disorders and generates a remarkable inhomogeneous broadening of the $\mathrm{Yb}^{3+}$ emission band as a result $[34,35]$. It is worth adding that in CALGO, the distance between the central metal ion and its ligand ion is so small $\left(0.19 \mathrm{~nm}\right.$ in isostructural $\left.\mathrm{CaYAlO}_{4}\right)$ that the crystal field splitting effect is much larger than that of most oxides [36]. This advantage also contributes to the broadening phenomenon. Additionally, the great thing for $\mathrm{Yb}$ : CALGO is that it not only possesses the aforementioned broadening effect, but also shows 
excellent stability because those two substitute ions $\left(\mathrm{Yb}^{3+}, 70\right.$ and $\left.\mathrm{Gd}^{3+}, 64\right)$ have trivial mass difference compared with $\mathrm{Yb}^{3+}(70)$ and $\mathrm{Ca}^{2+}(20)$ [37]. The lattice dimensions of $\mathrm{Yb}$ :CALGO are usually determined by X-ray diffraction method and the typical results carried out by Talik et al. recently are shown in Table 1 [38].

Table 1. Chemical and physical properties of Yb:CALGO [27,38-47].

\begin{tabular}{|c|c|c|c|}
\hline Chemical Properties & Values & Physical Properties & \multirow{8}{*}{$\begin{array}{c}\text { Values } \\
5.97 \mathrm{~g} / \mathrm{cm}^{3} \\
1840^{\circ} \mathrm{C} \\
n_{\mathrm{o}}=1.9331 \\
n_{\mathrm{e}}=1.9564 \\
\sim 95 \mathrm{fs}^{2} / \mathrm{mm} \\
\mathrm{d} n_{\mathrm{o}} / \mathrm{d} T=-7.6 \times 10^{-6} \mathrm{~K}^{-1} \\
\mathrm{~d} n_{\mathrm{e}} / \mathrm{d} T=-8.6 \times 10^{-6} \mathrm{~K}^{-1} \\
\sim 90 \mathrm{~nm}\end{array}$} \\
\hline Space group & $\mathrm{I}_{4} / \mathrm{mmm}\left(\mathrm{D}_{4 \mathrm{~b}}^{17}\right)$ & Density & \\
\hline symmetry & $\mathrm{C}_{4 \mathrm{v}}$ & Melting point & \\
\hline I attice dimencions & $\mathrm{a}=3.66 \AA$ & Rofractive inder & \\
\hline Lattice dimensions & $c=12.01 \AA$ & Refractive index & \\
\hline Lattice volume & $161.15 \AA^{3}$ & Group velocity dispersion & \\
\hline Molecular weight & $288.31 \mathrm{~g} / \mathrm{mol}$ & Thermo-optic coefficients & \\
\hline Occupation site & $\mathrm{Gd}^{3+} / \mathrm{Ca}^{2+}$ & Gain bandwidth & \\
\hline
\end{tabular}

\subsection{Spectroscopic Properties}

For the development of lasers, it is also crucial to analyze the spectroscopic properties including absorption bands and emission bands. A narrow absorption band such as that of $\mathrm{Nd}: Y A G$ usually demands high wavelength uniformity and precise temperature control of diode laser arrays, which poses challenges for concise system operation [48]. Luckily, the disordered structure of Yb:CALGO results in the inhomogeneous broadening effect, which brings out its intense, broad and flat bands. For familiar Yb-doped crystal $\mathrm{Yb}$ : YAG [49], the energy level structure is shown in Figure 1b. The transition energy between different stark sub-levels determines the corresponding photon absorption or emission wavelengths. However, for $\mathrm{Yb}: \mathrm{CALGO}$, the spectral line broadening is strengthened due to the non-equiposition exchange effect of $\mathrm{Ca}^{2+}$ ions, making the broadening of adjacent stark sub-levels exceed the energy gap. So, each sub-level does not have a certain energy value, as shown in Figure 1c. Therefore, instead of the traditional multi-peak structure, the absorption and emission spectrum structures present broad bands with main peaks shown in Figure 1d,e [50].

The Yb:CALGO crystal is optically uniaxial and the optical axis is parallel to the $\mathrm{c}$-axis $(c)$. Hence, there are two principle polarizations, when the polarization of light is parallel to the c-axis, it is $\pi$-polarization (or p-polarization, $E \| c$ ), when the polarization of light is perpendicular to the c-axis, it is $\sigma$-polarization (or s-polarization, $E \perp c$ ). It can be clearly seen from Figure $1 \mathrm{~d}$ that the absorption spectra are polarization-dependent and there exists an absorption peak at $979 \mathrm{~nm}$ owning to the zero-line transition between ${ }^{2} \mathrm{~F}_{5 / 2}$ and ${ }^{2} \mathrm{~F}_{7 / 2}$ manifolds. Besides, the absorption coefficient of the $\pi$ polarization is generally greater than that of the $\sigma$ polarization. The specific peak absorption cross-sections are $1 \times 10^{-20} \mathrm{~cm}^{2}(\sigma)$ and $2.7 \times 10^{-20} \mathrm{~cm}^{2}(\pi)$ [51], while the absorption bandwidth (full width at half maximum, FWHM) is $6 \mathrm{~nm}$ for $\pi$ polarization [20]. Note that the FWHM of $6 \mathrm{~nm}$ may not sound attractive enough, but actually the absorption cross-section takes considerable values in the range of $930 \mathrm{~nm}$ to $990 \mathrm{~nm}$ as shown in Figure 1d. Therefore, the absorption bands are broad enough to match with the emission wavelength of commercially InGaAs laser diodes even with a thermal shift of peak wavelength. As for the emission bands, researchers have conducted many experiments to evaluate the efficiency of this crystal. In general, the emission bands cover most of near-infrared spectral range from Figure 1e. The emission peak is around $1050 \mathrm{~nm}$, the fluorescence bandwidth (FWHM) is $80 \mathrm{~nm}$ for $\sigma$ polarization and a relatively high plateau $\left(0.75 \times 10^{-20} \mathrm{~cm}^{2}\right)$ exists between $1000 \mathrm{~nm}$ and $1050 \mathrm{~nm}$. This plateau was explained by two selective excitation experiments at the temperature of $10 \mathrm{~K}$, one of which adopted pumping light of $978 \mathrm{~nm}$ while another relied on pumping light of $983 \mathrm{~nm}$ [52]. Two complementary bands were shown clearly at $10 \mathrm{~K}$ but were combined into one single emission band with a plateau at $300 \mathrm{~K}$. In the emission wavelength range of $1000 \mathrm{~nm}$ to $1050 \mathrm{~nm}$ for the $\sigma$ polarization, the emission cross-section 
$\sigma_{e m}$ is $0.75 \times 10^{-20} \mathrm{~cm}^{2}$ and the fluorescence lifetime $\tau_{f}$ is $420 \mu \mathrm{s}$, leading to the product $\sigma_{e m} \tau_{f}$ being $315 \times 10^{-20} \mu \mathrm{s} \mathrm{cm}{ }^{2}[20]$.

\subsection{Thermal Characteristics}

In lasers, thermal regulation always plays a key role for better performance, as heavy heat loads lead to undesired thermal lensing effect and thermal stresses (even fracture of the crystal). They limit the output power scalability, affect the laser cavity stability and deteriorate output beam quality [53]. In terms of evaluating a crystal's thermal behavior, one should never ignore thermal expansion coefficient $\alpha$ and thermal conductivity $\kappa$. The former describes how crystals expand or shrink under different temperatures and the latter implies how fast crystals "breathe out" the redundant heat. At the very beginning [18], researchers measured unit cell parameters of Yb:CALGO by X-ray diffraction method under temperatures ranging from $300 \mathrm{~K}$ to $1400 \mathrm{~K}$. Based on obtained data, the exact thermal expansion coefficients were retrieved as $10.1 \times 10^{-6} \mathrm{~K}^{-1}$ along the a-axis and $16.2 \times 10^{-6} \mathrm{~K}^{-1}$ along the c-axis. Thermal conductivity values were determined to be as high as $6.9 \mathrm{~W} \cdot \mathrm{m}^{-1} \cdot \mathrm{K}^{-1}$ and $6.3 \mathrm{~W} \cdot \mathrm{m}^{-1} \cdot \mathrm{K}^{-1}$ along the a-axis and the c-axis, respectively, for a 2 at. \% Yb:CALGO sample. Note that $R_{P}$ is a new integrated figure of merit constructed by Petit et al. to reassess $\mathrm{Yb}$-doped laser materials in terms of thermo-mechanical properties and quantum defect, which is $R_{P} \propto \kappa^{2} / \alpha \eta$ with $\eta$ the quantum defect. Obviously, the larger $\kappa$ and the smaller $\alpha$ and $\eta$ (the larger $R_{P}$ ), the better crystal behaves. It turned out that the new-introduced 2 at. \% Yb:CALGO ranked 1st among 15 at. \% Yb:GGG, 2.7 at. $\% \mathrm{Yb}: \mathrm{Y}_{2} \mathrm{O}_{3}, 5$ at. \% $\mathrm{Yb}: \mathrm{YAG}, 5$ at. $\% \mathrm{Yb}_{\mathrm{CaF}}$ and $\mathrm{Yb}: \mathrm{KGW}$. Later on, to better understand this material's thermal advantage, researchers compared more $\mathrm{Yb}$-doped laser materials' thermal conductivities [54] and modeled to study the influence of the doping rate of $\mathrm{Yb}$ ions (i.e., $x$ of $\mathrm{CaGd}_{1-x} \mathrm{Yb}_{x} \mathrm{AlO}_{4}$ ) qualitatively and quantitatively. One of these models elaborately assumed that part of $\mathrm{Yb}$ ions substituted for $\mathrm{Gd}$ ions and the others substituted for $\mathrm{Ca}$ ions rather than all ions substituted for $\mathrm{Gd}$ ions. They also took the mass differences $\left(\mathrm{M}_{\mathrm{Gd}}=157.3 \mathrm{~g} / \mathrm{mol}, \mathrm{M}_{\mathrm{Yb}}=173 \mathrm{~g} / \mathrm{mol}, \mathrm{M}_{\mathrm{Ca}}=40.1 \mathrm{~g} / \mathrm{mol}\right.$, $\Delta \mathrm{M}_{\mathrm{Gd} / \mathrm{Yb}}=16$ and $\Delta \mathrm{M}_{\mathrm{Gd} / \mathrm{Yb}}=133$ ) into consideration. The result fit well with experimental measurements [29]. 


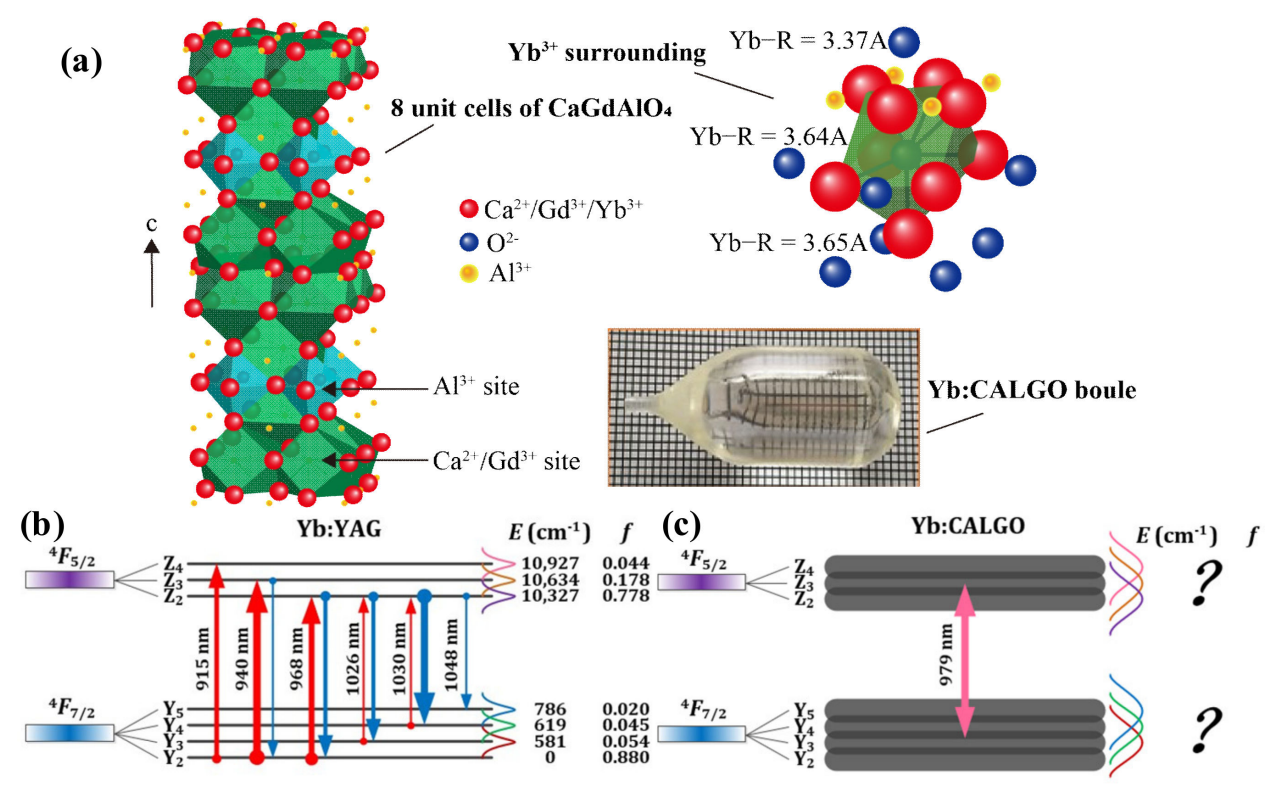

(d)

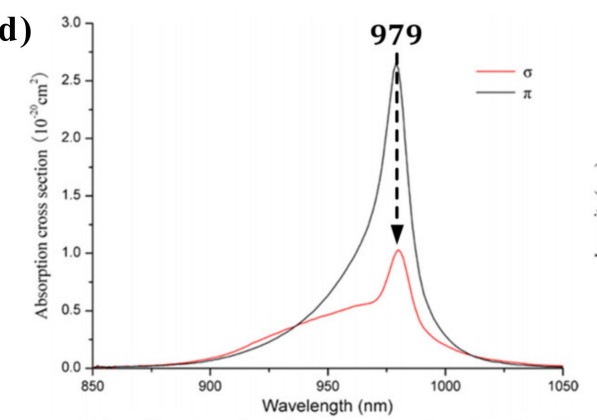

(f)

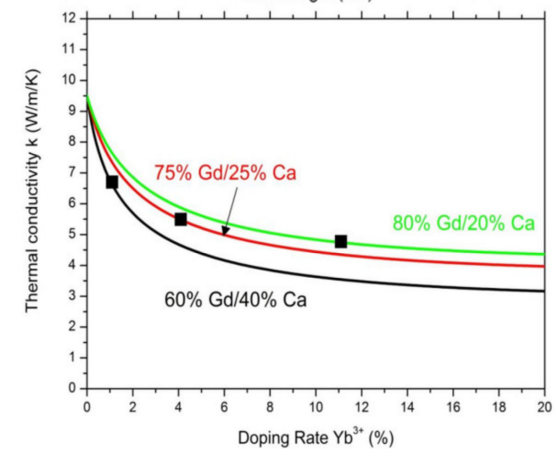

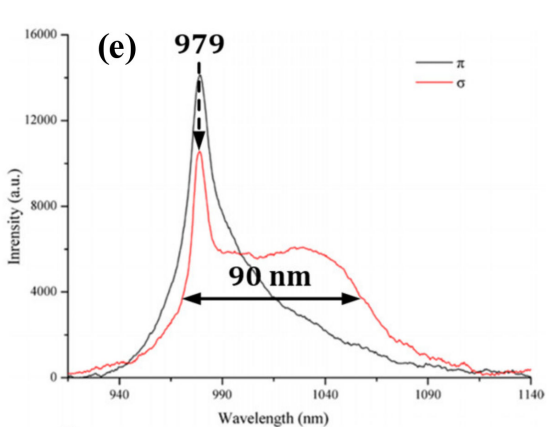

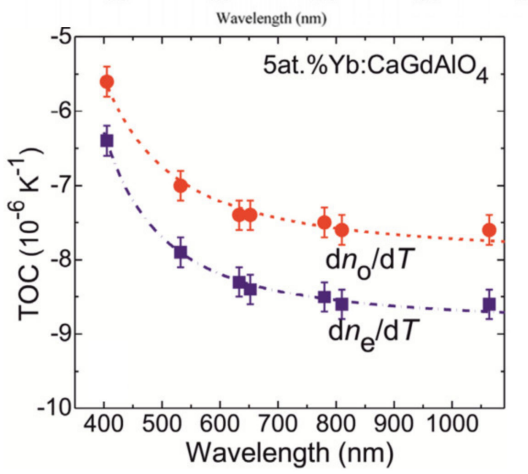

Figure 1. (a) Eight unit cells of $\mathrm{CaGdAlO}_{4}$ (left), local surrounding of $\mathrm{Yb}^{3+}$ in CALGO structure (upper right) and appearance of Yb:CALGO (lower right). Energy band structures of (b) Yb:YAG and (c) Yb:CALGO. The absorption (d) and emission (e) cross-sections of Yb:CALGO [28]. (f) Thermal conductivity versus doping rate of $\mathrm{Yb}^{3+}$ for different $\mathrm{Gd}^{3+} / \mathrm{Ca}^{2+}$ occupation site [29] and thermo-optic coefficient (TOC) versus wavelength in a 5 at. \% Yb:CALGO for the ordinary light and extraordinary light [37]. (a) The unit cell picture and local structure picture are redrawn based on ref. [26] and ref. [55], respectively. The Yb:CALGO boule picture is permitted for reuse by School of Crystal Materials (State Key Laboratory of Crystal Materials) of Shandong University, Group of Prof. Xutang Tao. (d,e) Reprinted with permission from ref. [28], IOP Publishing. (f) Left, reprinted with permission from ref. [29], SPIE. (f) Right, reprinted with permission from ref. [37], @The Optical Society.

Furthermore, for the sake of optimizing laser design, one needs to explore its thermo-optic coefficients (TOCs) and thermal coefficients of the optical path (TCOP) (see Figure 1f). The former figures are evaluated by $d n / d T$ while the latter is expressed by $W=d n / d T+(n-1) \alpha$, where $n$ is the refractive index, $T$ is the temperature and $\alpha$ is the thermal expansion coefficient. Considering that $\mathrm{Yb}: \mathrm{CALGO}$ is uniaxial, there are two principle TOCs and 
TCOP values. Pavel et al. first determined these figures of merit by laser beam deviation method [37]. They modeled to evaluate experiential analytic expressions for the thermo-optic dispersion formulas: $\frac{d n}{d T}(\lambda)=A_{0}+\frac{A_{1}}{\lambda^{2}}+\frac{A_{2}}{\lambda^{4}}+\frac{A_{3}}{\lambda^{6}}$, where $d n / d T$ is expressed in $10^{-6} \mathrm{~K}^{-1}$, wavelength $\lambda$ is in $\mu \mathrm{m}$ and $\mathrm{A}_{0-3}$ are the expansion coefficients. Later, they extended to investigate the dispersions of the refractive index in CALGO and CALYO laser host crystals and obtained the Sellmeier equations for the spectral range of $0.35-2.1 \mu \mathrm{m}$ as well as group velocity dispersion being positive at $\sim 1 \mu \mathrm{m}\left(95 \mathrm{fs}^{2} / \mathrm{mm}\right)$ and negative at $\sim 2 \mu \mathrm{m}\left(-40 \mathrm{fs}^{2} / \mathrm{mm}\right)$ for CALGO [27]. These encouraging results are especially valuable for high power mode-locked laser designs. Basically, the thermo-optical properties determine the thermal lensing effect. So, the same group directly measured the equivalent dioptric power of thermal lensing of $N g$-cut $\mathrm{Yb}: \mathrm{KGW}$ and $a$-cut $\mathrm{Yb}$ :CALGO in a similar laser setup. The comparison results showed that the Yb:CALGO crystal exhibited negligible anisotropy in the thermal lensing power [56].

\section{Advanced Progress}

As a highly anticipated gain medium, the first milestone of laser emissions achieved $600 \mathrm{~mW}$ at $1050 \mathrm{~nm}$ and lower power at shorter wavelength [18]. After that, enduring efforts of laser specialists have been paid to achieve exceptional results based on Yb:CALGO, either in a continuous-wave (CW) scheme or pulsed scheme, some of which are even record-breaking.

\subsection{Yb:CALGO in CW Lasers}

$\mathrm{Yb}: \mathrm{CALGO}$ in CW lasers shows its advantage in high power and high efficiency, broad wavelength and dual-wavelength tunability and, also, spatial mode tunability in structured beam lasers.

\subsubsection{High Power and High Efficiency Yb:CALGO Lasers}

In 2013, Calendron designed a novel laser cavity by introducing dual-crystal Yb:CALGO to reduce thermal lensing effect and successfully extracted $23 \mathrm{~W}$ of power at $1042 \mathrm{~nm}$ from 2 at. \% doped crystals under CW operation [57]. Meantime, Druon et al. leveraged a high-power pumping (up to $200 \mathrm{~W}$ ) technique as seen in Figure 2a and improved the CW output power to $43 \mathrm{~W}$ [58], which was a new record at that time. As high pump power (typically $>100 \mathrm{~W}$ ) leads to thermal problems, the thermal lens issue was studied in detail. It is noteworthy that they found the output could automatically stabilize from a high spatial multimode regime to a $\mathrm{TEM}_{00}$ mode, accompanied by a switch of polarization state from $\sigma$ to $\pi$. They analyzed this atypical behavior and credited it to the special spectroscopic and thermal properties of Yb:CALGO. Later, Kore's group grew the crystal with doping concentration up to 10 at. \% in their lab and reached maximum CW output $3.3 \mathrm{~W}$ of power, $73 \%$ of slope efficiency and $65 \%$ of optical-to-optical efficiency [59]. For the sake of integration, they also designed the first femtosecond-laser-written waveguide laser in $\mathrm{Yb}$ :CALGO as depicted in Figure 2b, emitting CW output up to $2.4 \mathrm{~W}$ of power and $69 \%$ of efficiency. They recently updated the waveguide Yb:CALGO laser with $3.9 \mathrm{~W}$ output at a slope efficiency of $67 \%$ [60]. To better illustrate the potential of Yb:CALGO crystal, Sujith et al. directly compared the performances of CW diode-pumped Yb:CALGO and $\mathrm{Yb}: \mathrm{KYW}$ lasers in a similar setup for the first time. They found that in terms of optical efficiency, the $\mathrm{Yb}: \mathrm{KYW}$ laser outperformed the Yb:CALGO one in the low power regime. However, the $\mathrm{Yb}$ :CALGO laser indeed did a much better job on thermal behavior in the high power regime [61]. Except for those encouraging results of laser emission, researchers also conducted investigation on the intracavity loss measurement in a diode-pumped CW $\mathrm{Yb}$ :CALGO laser by spectroscopic gain analysis method or the Findlay-Clay analysis [62], which aided in high-efficiency and high-power laser systems. 

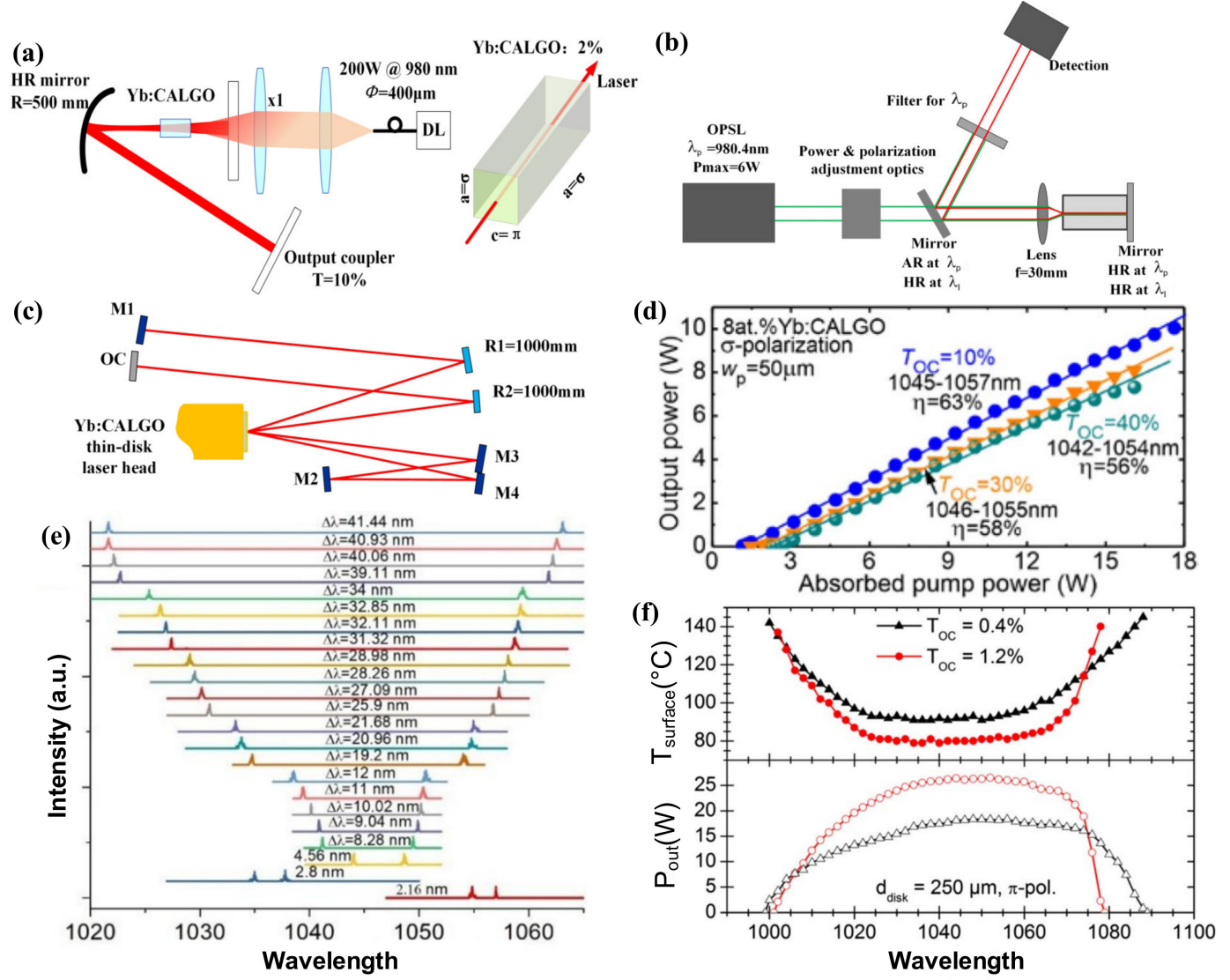

Figure 2. (a) A high-power Yb:CALGO oscillator [58]. (b) The first fs-laser-written waveguide laser in Yb:CALGO [59]. (c) High-efficiency Yb:CALGO thin disk [63]. (d) The performance of the first Yb:CALGO microchip laser [41]. (e) Dualwavelength [64] and (f) broad wavelength-tunable [43] lasers. (a-c) are redrawn based on refs. [58,59,63], respectively. (d) Reprinted with permission from ref. [41], (OThe Optical Society. (e) Reprinted with permission from ref. [64], SPIE. (f) Reprinted with permission from ref. [43], (T) Optical Society.

Another interesting point to note is the parallel progress done on thin-disk (TD) lasers and microchip lasers. A TD oscillator uses a very thin crystal cooled on its back side for efficient cooling and recycling multi-pass pump configuration to obtain appreciable absorption of pump light. The advantages of this structure plus large emission bandwidth and good thermal properties of Yb:CALGO crystal enable efficiency-enhanced or powerscaled laser systems. In 2012, Ricaud's group first created an Yb:CALGO TD laser in CW regime and obtained $29.5 \mathrm{~W}$ of average power, $40 \%$ of slope efficiency and $32 \%$ of opticalto-optical efficiency as shown in Figure 2c [65]. It is interesting that they discussed the main bottlenecks of this crystal, which were the difficulties to diminish scattering losses and to obtain high optical quality crystal. What follows is a thin-disk laser configuration with slope efficiency of $70 \%$, optical-to-optical efficiency of $57 \%$ and maximum output power of $30.7 \mathrm{~W}$ [43]. They were the highest efficiencies achieved on this medium at that time. Years after, Pavel et al. first presented a microchip laser scheme to break the record and the slope efficiency was as high as $84 \%$ shown in Figure $2 \mathrm{~d}$ (near the quantum-defect-limited slope efficiency) [41]. Actually, they conducted the experiments on $\mathrm{Yb}: \mathrm{CaLn} \mathrm{AlO}_{4}(\mathrm{Ln}=\mathrm{Gd}$, $\mathrm{Y})$ and the efficiency of $\mathrm{Yb}: \mathrm{CaYAlO}_{4}$ was even higher (91\%), near the upper limit indeed. They adopted a $3.4 \mathrm{~mm}$-long, 8 at. \%Yb:CALGO and obtained $7.79 \mathrm{~W}$ of output power correspondingly and compared the outputs of two crystals as well. Notably, the microchip laser scheme has been envisaged to foster miniaturization. 


\subsubsection{Broad Wavelength and Dual-Wavelength Tunable Yb:CALGO Laser}

Thanks to the peculiar spectroscopic properties of Yb:CALGO crystal, dual- and tunable-wavelength lasers were also reported at the same time. The first laser emission of this crystal in 2005 demonstrated its potential in tunability [18]. In 2008, Boudeile et al. studied the relation between its tunability and doping concentration under CW $100 \mathrm{~W}$ of pump power [66]. The results showed that higher doped crystal may possess a broader emission spectrum and some other factors such as crystal length also mattered to the bandwidth. However, all emission band were quite broad and the broadest one ranged from $\sim 1010 \mathrm{~nm}$ to $\sim 1082 \mathrm{~nm}$. Then, Calendron demonstrated its tunability ranging from $1018 \mathrm{~nm}$ to $1060 \mathrm{~nm}$ while the powers were beyond $15 \mathrm{~W}$ between $1030 \mathrm{~nm}$ and $1057 \mathrm{~nm}$ [57]. The aforementioned TD and microchip lasers were also tunable with the ranges from $1018 \mathrm{~nm}$ to $1052 \mathrm{~nm}$ [65], from $999 \mathrm{~nm}$ to $1089 \mathrm{~nm}$ (the widest) [43] and from $1057 \mathrm{~nm}$ to $1065 \mathrm{~nm}$ [41]. In addition to single-wavelength tunability, dual-wavelength $\mathrm{Yb}$ :CALGO lasers were presented and studied as well. A dual-wavelength oscillator can simultaneously emit two wavelengths laser output and is highly suitable for applications in $\mathrm{THz}$ generation [67], optical coherence tomography [68], etc. In 2018, Sujith et al. invented a discretely tunable dual-wavelength $\mathrm{Yb}$ :CALGO laser using a single birefringent filter (BRF) plate [69]. BRF plates can introduce wavelength-dependent periodic loss into a standard laser cavity. They not only achieved discrete frequency offset ranging from $1.3 \mathrm{THz}$ to $12.5 \mathrm{THz}$ by BRFs with thicknesses of $0.5,2,4$ and $6 \mathrm{~mm}$ but also yielded multi-watt output power (maximum $4.1 \mathrm{~W}$ ), which were applicable and economical to further design dual-wavelength modelocked lasers and generate $\mathrm{THz}$ radiations. Recently, Reza et al. utilized a similar BRF plate (12 mm thick) to demonstrate a CW dual-wavelength Yb:CALGO laser (see Figure 2e) [64]. It is noteworthy that the wavelength spacing changed from $2.16 \mathrm{~nm}$ to $41.44 \mathrm{~nm}$ by rotating the BRF and the output power was as high as $\sim 7.5 \mathrm{~W}$ for $25 \mathrm{~W}$ of the incident pump power. In addition, as for single-wavelength tunability, Liang's group studied the dependence of emission wavelength on the crystal temperature [70]. They first observed that by increasing absorbed pump power, the temperature of the Yb:CALGO crystal also increased, which led to the output wavelength variation from $1051.10 \mathrm{~nm}$ to $1054.72 \mathrm{~nm}$. In short, a Yb:CALGO laser can feature wavelength tunability in both single-wavelength and dual-wavelength operation configurations. The following sections in this review about pulsed-scheme lasers or structure-beam lasers (see below) also demonstrate this feature.

\subsubsection{Mode-Tunable Structured Light Lasers with Yb:CALGO}

Many laser scientists focus peculiarly on how to design a laser with higher output power or higher energy or higher repetition rate, whilst the transverse profiles of laser beams are equally meaningful since they lend support to applications in optical manipulation, next generation large-capacity communication, microscopy, measurement, etc. [71,72]. These beams are collectively known as structured beams including vortex beams [73], nondiffracting beams [74], self-accelerating beams [75], among many others. Over the past decades, there are seminal research advances in lasers that directly emit structured beams for the sake of high mode purity and power [76]. Our group first presented the experiments on Yb:CALGO structured beam lasers [77]. In a CW scheme, by controlling the dual-offaxis displacements and pump power, wavelength-tunable high order Hermite-Gaussian (HG) modes were excited at will, as illustrated in Figure 3a. The experimentally measured wavelength-tunable range was $10 \mathrm{~nm}$ and mode-tunable range was up to 15 modes. We also transformed the HG modes to corresponding Laguerre-Gaussian modes by a pair of cylindrical lenses and produced more valuable vortex beams carrying orbital angular momenta $(\mathrm{OAM})$. Later, we reported the dual-wavelength vortex beams $(1046.1 \mathrm{~nm}$ and $1057.2 \mathrm{~nm})$ and tested the laser's spectral stability (steadily operated for more than $3 \mathrm{~h}$ ) as well [78]. When the cavity geometry satisfies the reentrant confinement of the coupled quantum harmonic oscillator in SU(2) Lie algebra [79], the frequency-degeneracy laser modes will be excited. Under this premise, we successfully explored vortex lattices with transverse-modelocking states [80], periodic-trajectory-controlled and wavelength-tunable SU(2) geometric 
modes [81] as well as polygonal vortex beams [82]. Not long ago, a new Yb:CALGO laser scheme was proposed by inserting two cylindrical lenses into the cavity to surprisingly obtain two-dimensional tunable high order HG modes as shown in Figure 3b [83]. This is significant because the elegant scheme was able to directly control two indices of HG modes at the source and after an astigmatic converter, the LG modes were tunable likewise. With more precise adjustments on the oscillator, chirality-controllable vortex beams were also achieved. By slightly modifying the angle of the output coupler, the OAM beam with wavelength tunability could be generated directly from Yb:CALGO laser recently [84]. An alternative vortex beam generator was also demonstrated with a mirror curvature dynamically controlled Z-shaped resonator in Figure 3c [85]. Researchers also found that by rotating the $\mathrm{Yb}$ :CALGO crystal in the cavity, vortex arrays could be produced directly as well [86]. Another interesting structured beam is the conical refraction (CR) light, i.e., a hollow cylinder light with annular intensity profile after the beam propagates conically through a laser crystal [87]. When the light rings of the CR beam are separated by a dark ring (dubbed Poggendorff dark ring), it is considered as excellent CR beam. Reza et al. recently investigated a $\mathrm{Yb}: C A L G O-b a s e d ~ C R$ laser and obtained CR beam with $6.25 \mathrm{~W}$ output power as well as an excellent CR beam with high quality [88].

(a)
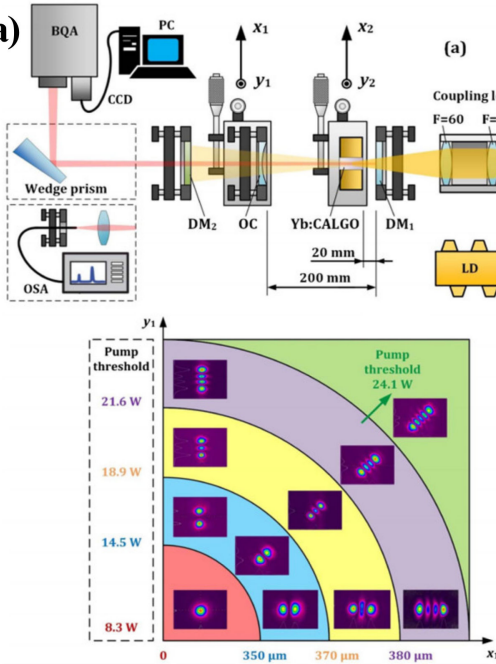

(b)
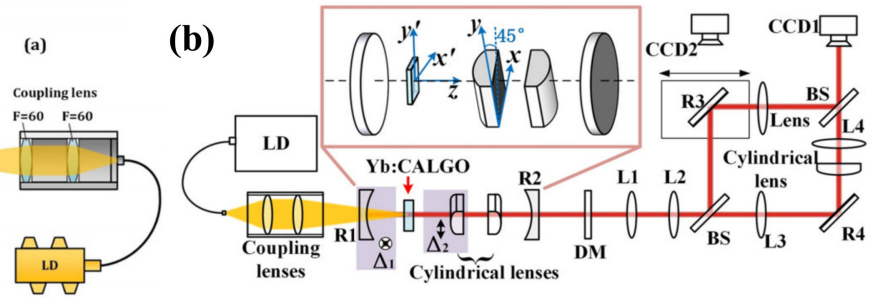

(c)

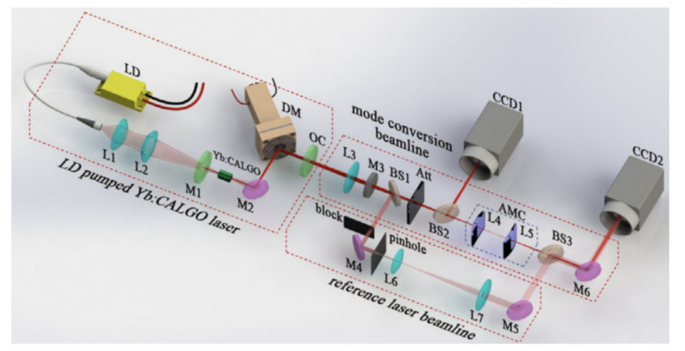

Figure 3. (a) Wavelength- and OAM-tunable Yb:CALGO laser [77]. (b) Two-dimensional tunable high order mode laser [83]. (c) Mode-tunable laser based on a mirror curvature dynamically controlled Z-shaped resonator [85]. (a) Reprinted with permission from ref. [77], (OThe Optical Society. (b) Reprinted with permission from ref. [83], the American Physical Society. (c) Reprinted with permission from ref. [85], (OThe Optical Society.

\subsection{Yb:CALGO in Ultrashort Pulse Lasers}

Previous endeavors care about CW laser emissions, and actually, the sought-after characteristics of $\mathrm{Yb}: \mathrm{CALGO}$ including good thermal properties and broad spectrum have fueled fertile research activities on pulsed laser output, in particular, ultrashort pulses (typically a few tens of femtoseconds). Femtosecond laser sources lay the foundation for many applications such as microfabrication [5], LIDAR [89] and laser-initiated systems [90] due to its high temporal confinement of energy. The recipe of generating ultrashort pulses is to lock many longitudinal modes of a laser cavity in phase whereby these modes interfere constructively to achieve short pulses, also termed as mode-locked (ML) laser oscillators [91]. Several milestones of ML lasers were established with the emergence of various laser media: femtosecond dye laser first, titanium-doped sapphire, then, $\mathrm{Cr}^{4+}{ }^{4}$, $\mathrm{Nd}^{3+}-, \mathrm{Cr}^{3+}$ - and $\mathrm{Yb}^{3+}$-doped crystals also [39]. In this regard, we review the major progress involved in the generation of ultrafast pulses initiated with $\mathrm{Yb}$ :CALGO.

Firstly, an inherent condition that ultrashort pulses need to satisfy is $\Delta t \Delta v \geq 0.32$ where $\Delta t$ and $\Delta v$ are the FWHM time duration and spectrum of a pulse, respectively. 
Obviously, to achieve shorter pulses, the laser medium should allow a broader spectrum to be amplified [39]. Indeed, the emission band width (FWHM) of Yb:CALGO is as broad as $80 \mathrm{~nm}$ (see Section 2) and the theoretical minimum duration is approximated to be $14 \mathrm{fs}$.

\subsubsection{Ultrashort Pulses with SESAM Mode Locking in Yb:CALGO Lasers}

The first pulsed emission dating back to 2007 was $47 \mathrm{fs}$ achieved by leveraging a semiconductor saturable-absorber mirror (SESAM) [50]. Since SESAM-based ML architecture is prevailing due to concise structure, self-starting, stable and good beam quality, we here summarize related pulsed emissions by Yb:CALGO. Soon after 2007, 40 fs pulses were enabled by a $350 \mathrm{~mW}$ single-mode laser pump with optimized ML performance [92]. In terms of average power, $68 \mathrm{fs}$ pulses with $520 \mathrm{~mW}$ at a $105 \mathrm{MHz}$ repetition rate were realized, updating the highest power for sub-100 fs Yb-bulk lasers [52]. This record was soon broken by Alessandro et al. by generating $95 \mathrm{fs}$ pulses with average power $12.5 \mathrm{~W}$ at an $80 \mathrm{MHz}$ repetition rate [93]. They set up a standard Z-cavity and a $4 \mathrm{~mm}$ long, 2 at. \% doped Yb:CALGO crystal was used. Note that $12.5 \mathrm{~W}$ may not be the upper limit because the available pump power for them was only up to $62.5 \mathrm{~W}$. Except for tunable CW output, pulsed emissions by $\mathrm{Yb}$ :CALGO are adjustable in wavelength too. Aforementioned, $40 \mathrm{fs}$ pulses were tunable across $20 \mathrm{~nm}$ [92] and a similar scheme could emit sub-100 fs pulses covering a $38 \mathrm{~nm}$ wide wavelength range between $1034 \mathrm{~nm}$ and $1072 \mathrm{~nm}$ [94]. It is interesting for $\mathrm{Yb}$ :CALGO because it also enlightened researchers to investigate the tunable performance output by $\mathrm{Yb}: \mathrm{CaYAlO}_{4}$, another new laser crystal similar to $\mathrm{Yb}: \mathrm{CALGO}$, which achieves broad tunability of $40 \mathrm{~nm}$ and pulse width as short as $43 \mathrm{fs}$ [95].

Soliton ML scheme is interesting since it keeps pulses away from pulse broadening [96], a deleterious effect that may cause signal crosstalk. This ML scheme happens when self-phase modulation (SPM) cancels group delay dispersion. Phillips et al. tested the soliton ML output of $\mathrm{Yb}$ :CALGO through cascaded quadratic nonlinearities [97]. Additionally, an intracavity LBO crystal offered large and negative SPM leading to pulses of $114 \mathrm{fs}$ at $1050 \mathrm{~nm}$ with a repetition rate of $113 \mathrm{MHz}$. Later on, they adopted a two-dimensionally patterned quasi-phase-matching (QPM) grating to better regulate the intracavity solitons and theoretically explained the new approach for pulse formation and stabilization [98]. Another milestone was established by them in terms of pulses with high repetition rate [99], as shown in Figure 4a, which could be helpful in spectroscopy and ultra-high-speed optical communications. In 2014, Alexander et al. realized a gigahertz $\left(10^{9} \mathrm{~Hz}\right) \mathrm{Yb}$ :CALGO laser, reaching $1.8 \mathrm{GHz}$ and $59.4 \mathrm{fs}$ without resort to external pulse compression indeed [100]. Mayer et al. addressed several considerable issues of ML lasers, which were, respectively, the strict need for single mode pump, low output power, Q-switching instabilities and bulky cavity geometries [99]. The recipe was the aforementioned intracavity multifunctional two-dimensionally patterned QPM device, which shaped the pulses in time, minimized the intracavity loss and acted as a dynamic self-defocusing lens to protect the cavity elements simultaneously. The encouraging pulses with $166 \mathrm{fs}$ of duration, $1.2 \mathrm{~W}$ of average output power and $10.6 \mathrm{GHz}$ of repetition rate greatly demonstrated the potential of $\mathrm{Yb}$ :CALGO. Very recently, they adopted the similar scheme to investigate how intracavity dispersion, pump and cavity design could affect ML performance [101]. By pumping with a higher brightness source and designing new dispersion-optimized dichroic outputcoupling cavity mirrors, $108 \mathrm{fs}$ pulses at $10.4 \mathrm{GHz}$ with an $11.6 \mathrm{~nm}$-wide optical spectrum and average output power of $812 \mathrm{~mW}$ were demonstrated. The pulses were further used to verify coherent octave-spanning supercontinuum generation in a silicon nitride waveguide. Another common technique to obtain high repetition rate pulses with an easy set-up is called harmonic mode locking [102]. In 2017, a SESAM ML Yb:CALGO oscillator with harmonic repetition rate operation up to the third order $(282 \mathrm{MHz})$ was realized [103]. Very soon, another $\mathrm{Yb}$ :CALGO laser with a harmonic repetition rate up to the 300th order was achieved, leading to $22.4 \mathrm{GHz}$ repetition rate in total [104]. They employed the amplified etalon effect of the laser crystal and the scheme was neat enough for sub-picosecond high repetition rate (over $10 \mathrm{GHz}$ ) oscillators. 


\subsubsection{Ultrashort Pulses with Kerr-Lens Mode-Locking in Yb:CALGO Lasers}

A counterpart of SESAM-based ML regime is the Kerr-lens mode-locking (KLM) technique. Researchers tried to obtain short pulses with high average powers from a Yb:CALGO oscillator operating at pure KLM mode [44], as shown in Figure 4b. Pumped by a highbrightness fiber laser, $40 \mathrm{fs}$ pulses with average power up to watt level were achieved and the shortest results were down to $32 \mathrm{fs}$, which was close to the theoretical limit. In terms of tunability, Gao et al. tuned the KLM-based wavelength output from $1043.5 \mathrm{~nm}$ to $1076 \mathrm{~nm}$ by tilting the end mirror of the cavity while maintaining the sub-100 fs time duration [105]. Though high repetition rate pulses are desirable in many cases, some scenarios, such as the micromachining of glasses, prefer lower repetition rates. By carefully managing the dispersion and ML process, Papadopoulos et al. filled the blank by successfully generating $93 \mathrm{fs}$ pulses at $27 \mathrm{MHz}$ and $170 \mathrm{fs}$ pulses at $15 \mathrm{MHz}$ through an extended-cavity ML Yb:CALGO laser [106]. The performances were scaled by Manjooran et al. in 2017 by creating pulses with $650 \mathrm{~mW}$ of average output power and $66 \mathrm{fs}$ of duration at a low repetition rate of $10.2 \mathrm{MHz}$ in a KLM scheme [107]. Correspondingly, the pulse energy was $64 \mathrm{~nJ}$ with a peak power of $0.97 \mathrm{MW}$, which was favorable in nonlinear microscopy, high harmonic generation and so on. Based on KLM, Kimura et al. recently used stimulated Raman scattering in three oscillators with different crystals ( $\mathrm{Yb}: \mathrm{CALGO}, \mathrm{Yb}: \mathrm{KY}\left(\mathrm{WO}_{4}\right)_{2}$ and $\left.\mathrm{Yb}: \mathrm{Y}_{2} \mathrm{O}_{3}\right)$ to produce ultrashort pulses, which is a new spectral broadening method [108]. The pulse durations from the Yb:CALGO oscillator were $22 \mathrm{fs}$, which were two thirds shorter than that of unbroadened ML pulses. To overcome the spectral and power limitations of collinearly pumped ultrashort lasers, Layaye et al. designed a cross-polarized pumping regime and obtained $31 \mathrm{fs}$ pulses with $389 \mathrm{~mW}$ of average power and 29\% efficiency recently [109]. Newly, Wang et al. delivered pulses with the shortest duration (4.8 optical cycles) ever reported for a KLM Yb-bulk laser [110]. By introducing two broadband chirped mirrors and a prism pair to regulate the intracavity dispersion, as shown in Figure $4 \mathrm{~d}, 17.8 \mathrm{fs}$ pulses with $26 \mathrm{~mW}$ of average power at $95.9 \mathrm{MHz}$ were triggered, indicating compelling performance brought by this special crystal. Such a few-cycle pulse is thought to only be achievable by transition-element-doped laser media (e.g., Ti:Sapphire) at $\sim 800 \mathrm{~nm}$. Now, $\mathrm{Yb}$ :CALGO opens a new possible platform to pursue extreme ultrashort sub-5-cycle pulses at $\sim 1 \mu \mathrm{m}$.

\subsubsection{Ultrashort Pulses from SESAM and Kerr-Lens Mode-Locked Yb:CALGO Lasers}

When SESAM and KLM are not considered separately, some scientific problems about laser pulses may have better solutions. In 2015, an all-optical Q-switching limiter was proposed to increase the Q-switching stabilities and output power in the gigahertz regime [111]. The key was the appropriate cavity design where a negative saturable absorber induced Kerr-lens effect held the maximum influence on the SESAM. Soon, Wang et al. enabled the Yb:CALGO laser to work in the SESAM combined Kerr-lens mode locking regime and reported the output pulses with duration of $70 \mathrm{fs}$ and FWHM of $19.8 \mathrm{~nm}$ at output power of $210 \mathrm{~mW}$, while in SESAM-only regime, the pulses were with duration of $630 \mathrm{fs}$ and FWHM of $2.7 \mathrm{~nm}$ at output power of $385 \mathrm{~mW}$ [112]. Moreover, their configuration allowed for the laser operation with both high output power and short pulse duration [113]. A working example is the $45 \mathrm{fs}$ pulses with $1.7 \mathrm{MW}$ of peak power directly from the oscillator achieved by the combined effects of Yb:CALGO crystal properties, efficient pumping and the dual action of KLM and SESAM [45], shown in Figure 4c. In their experiments, pulses could be as short as $38 \mathrm{fs}$ with peak power of $187 \mathrm{~kW}$. 


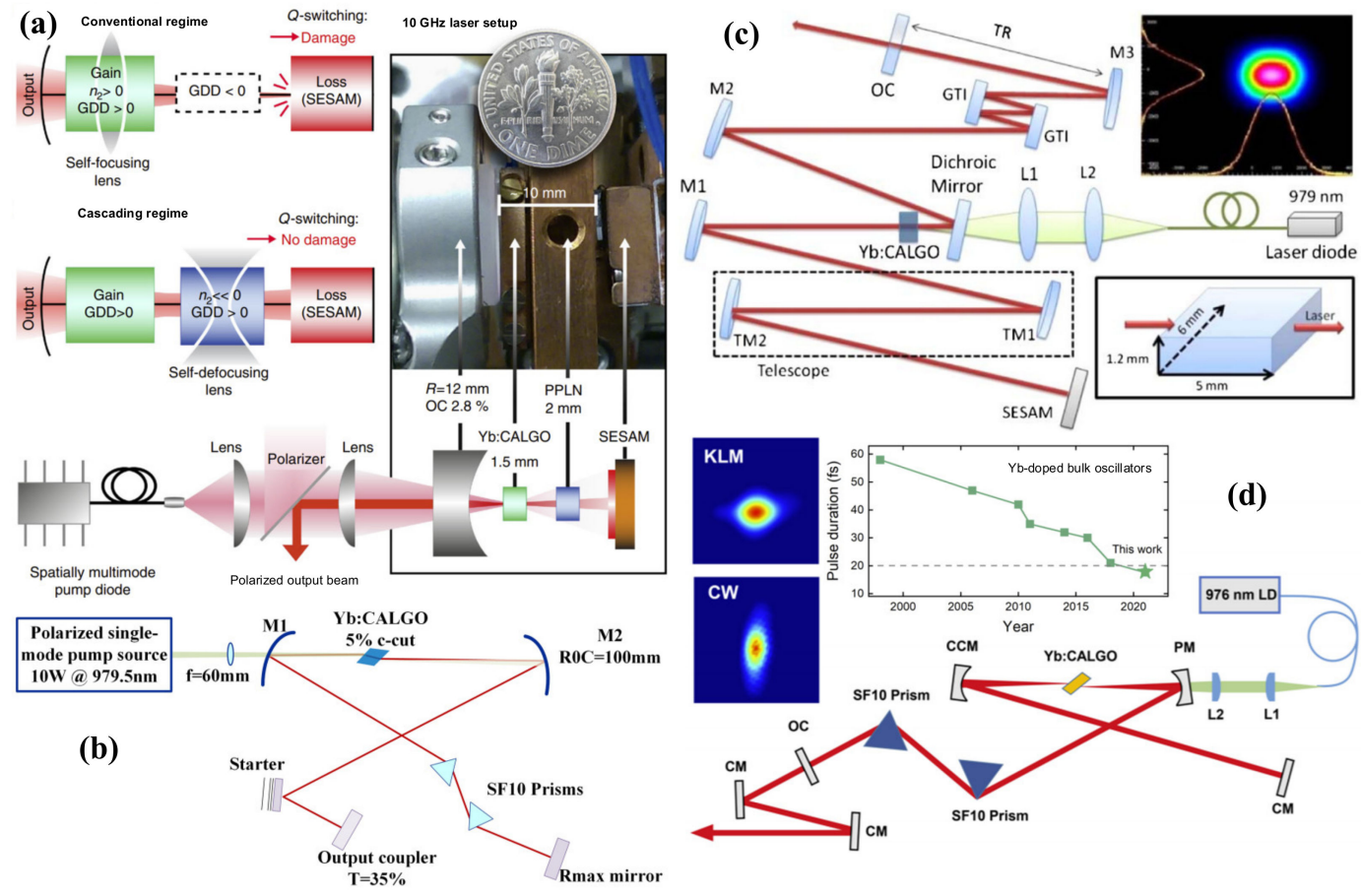

Figure 4. Ultrashort pulse Yb:CALGO lasers by leveraging (a) SESAM mode locking [99], (b) Kerr-lens mode locking [44], (c) both SESAM and Kerr-lens mode locking [45] and (d) Kerr-lens mode locking with broadband chirped mirrors and a prism pair [110] techniques. (b) is redrawn based on ref. [44]. (c) Reprinted with permission from ref. [45], (OThe Optical Society. (d) Reprinted with permission from ref. [110], (0The Optical Society.

\subsubsection{Ultrashort Pulses with Other Methods in Yb:CALGO Lasers}

Different from above ML scheme, Tong et al. recently used a nonlinear mirror ML scheme to design a pulsed $\mathrm{Yb}$ :CALGO laser for the first time [114]. As shown in Figure 5a, they constructed the nonlinear mirror by a BBO crystal and a dichroic mirror and obtained stable picosecond (2.3 ps) solid-state $1052 \mathrm{~nm}$ laser with an average power of $1.78 \mathrm{~W}$ and repetition rate of $116 \mathrm{MHz}$.

To acquire pulses with high energy and power, an alternative technique is regenerative amplifier (RA) whereby a seeded pulse is amplified by gain crystals and then compressed by gratings. The first Yb:CALGO RA was released by Caracciolo et al., as shown in Figure $5 \mathrm{~b}$, with $650 \mathrm{~mW}$ and 92 fs seed pulses being amplified and compressed to $28 \mathrm{~W}$ and $217 \mathrm{fs}$ pulses at $500 \mathrm{kHz}$ repetition rate [115]. What follows were $1 \mathrm{~nJ}$ seed pulses being augmented to $3 \mathrm{~mJ}$ achieved by Calendron [57]. For RAs, ultrashort pulse duration generally contradicts with high power/energy. Pouysegui et al. addressed this issue through a complex amplifier scheme, and the pulses with $97 \mathrm{fs}$, up to $24 \mu \mathrm{J}$, centered at $1047 \mathrm{~nm}$ and at $50 \mathrm{kHz}$ repetition rate were reported [116]. In terms of high pulse energy and high repetition rate, Caracciolo et al. also compared the performances of $\mathrm{Yb}: C A L G O-$ and $\mathrm{Yb}: \mathrm{CaF}_{2}$-based RAs where both crystals admitted $1 \mathrm{~mJ}$ pulses with sub$400 \mathrm{fs}$ at $5 \mathrm{kHz}$ [51]. Then, they proposed a brand new intracavity pulse stretching design by exploiting a single grating mirror, which simplified the layout and extracted $193 \mathrm{fs}$ pulses with $205 \mu \mathrm{J}$ at $20 \mathrm{kHz}$ repetition rate [117], as shown in Figure 5c. Yb:CALGO amplifier can also be used for the generation of low noise optical frequency comb lately, showing great potential in frequency metrology and high-resolution spectroscopy [118]. Moreover, a high-power $\mathrm{Yb}$ :CALGO regenerative amplifier system was also demonstrated to generate pulses with $11 \mathrm{~W}$ average power, $50 \mathrm{fs}$ pulse width, $3.7 \mathrm{GW}$ peak power and $43 \mathrm{kHz}$ repetition rate, all at the same time and for the first time [119]. The scheme was also the first sub-100 fs regenerative amplifier based on Yb-doped bulk medium without nonlinear spectral broadening, showing conciseness and robustness. 
(a)

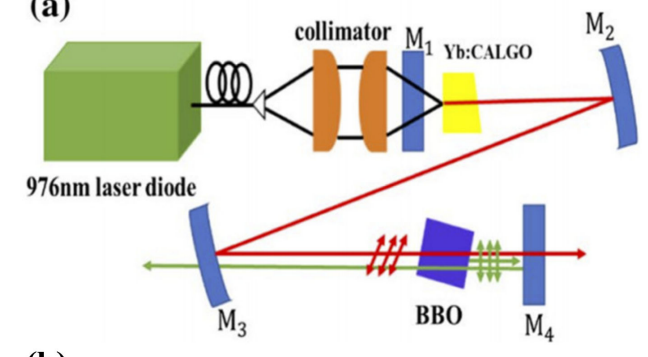

(b)

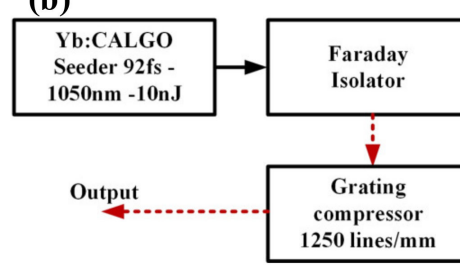

(c)

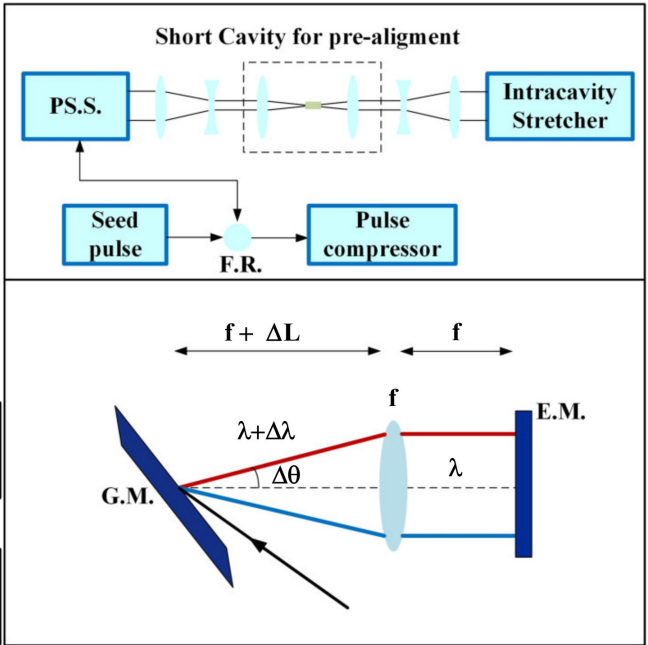

Figure 5. (a) Ultrashort pulses Yb:CALGO lasers with nonlinear mirror ML scheme [114]. (b) The first Yb:CALGO RA [115]. (c) A new intracavity pulse stretching design by exploiting a single grating mirror [117]. (a) Reprinted by permission from ref. [114], Springer Nature. (b,c) are redrawn based on ref. [116] and ref. [118], respectively.

\subsubsection{Ultrashort Pulses in Thin-Disk Yb:CALGO Lasers}

In concurrence with bulk schemes, there are also efforts on pulsed oscillators in special schemes. The first ML thin-disk laser was addressed in 2012 by Ricaud et al. and sub-200 fs pulses at watt level ranging from $1032 \mathrm{~nm}$ to $1046 \mathrm{~nm}$ were extracted as well as $300 \mathrm{fs}$ pulses with average power of $28 \mathrm{~W}$ or $197 \mathrm{fs}$ pulses with an average power of $20 \mathrm{~W}$ [120]. The promising properties of $\mathrm{Yb}$ :CALGO also enabled pulses with $15 \mathrm{~nm}$ width (FWHM) and millijoule-level energy in a similar TD regime [63]. The results were soon improved by Diebold et al. with attractive features such as $62 \mathrm{fs}$ pulse width at a repetition rate of $65 \mathrm{MHz}$, average power of $5.1 \mathrm{~W}$ and peak power of $44 \mathrm{MW}$ in a SESAM-based TD oscillator [121]. In addition, KLM-based TD laser was also demonstrated recently, with the shortest pulses of any TD oscillators [122]. The $30 \mathrm{fs}$ pulses with average power $150 \mathrm{~mW}$ were not only well matched with that of Yb-doped bulk oscillators, but also could be shorter for the direct generation of few-cycle pulses in their regime with further optimization.

\section{Conclusive Remarks}

To conclude, Yb:CALGO, as a new laser crystal, possesses outstanding properties including ultrabroad and flat-top emission spectrum and large thermal conductivity as well as stable thermo-optic characteristics. Based on these advantages, Yb:CALGO has become an increasingly important candidate of laser gain media for generating versatile structured light with largely improved properties, both in CW lasers towards tunable light and in pulsed lasers towards extremely short and intense light. In the past 15 years since it was proposed, $\mathrm{Yb}$ :CALGO lasers have set up several records in diverse laser technologies:

(1) Yb:CALGO produced the ultrafast lasers with highest intracavity peak power of 44 MW [121].

(2) Yb:CALGO laser reached the highest slop efficiency as $84 \%$ (near the quantum-defectlimited slope efficiency) in a microchip laser scheme [41].

(3) Yb:CALGO empowered a wavelength-tunable laser with a tuning range as broad as $90 \mathrm{~nm}[43]$.

(4) Yb:CALGO permitted the highest peak power of $1.7 \mathrm{MW}$ in a sub-50 fs diode-pumped laser oscillator [45].

(5) Yb:CALGO could operate in a microchip laser with length of $3.4 \mathrm{~mm}$ and produced multi-watt emission [41].

(6) Yb:CALGO allowed a new mode-locking regime producing $100 \mathrm{fs}$ pulses at $540 \mathrm{MHz}$ repetition rate with $760 \mathrm{~mW}$ of average output power [98]. 
(7) Yb:CALGO enabled direct emission of watt-level 10-gigahertz pulses from a simple and small straight laser cavity [99].

(8) Yb:CALGO created the shortest pulses with time duration of $17.8 \mathrm{fs}$ in a Kerr-lens mode-locked architecture [110].

(9) Yb:CALGO optical frequency comb created the narrowest free-running CEO linewidth as $1.6 \mathrm{kHz}$ and a comb optical linewidth narrower than $28 \mathrm{kHz}$ in $1 \mathrm{~ms}$ observation time at $1064 \mathrm{~nm}$ [118].

(10) Yb:CALGO-based regenerative amplifier demonstrated the first sub-100 fs pulses with $11 \mathrm{~W}$ average power, $3.7 \mathrm{GW}$ peak power and $43 \mathrm{kHz}$ repetition rate without resorting to nonlinear spectral broadening [119].

We anticipate that the Yb:CALGO will rapidly create more and more amazing records of laser technology in the near future. Despite the exciting progresses and advantages discussed above, currently, Yb:CALGO also has some challenges in terms of regulating scattering losses and growing high optical quality crystal, which can sharply impair the laser performance. So, the results of experimental gain measurement were lower than expected indeed. These drawbacks may be potentially addressed by more advanced crystal growth technique.

Furthermore, structured light with the control of multiple degrees of freedom using $\mathrm{Yb}$ :CALGO lasers can also be a hot topic, including ultrafast temporal-tunable, spectraltunable and spatial-tunable vortex beams, which have promised tremendous applications such as optical tweezers, large-capacity communications. On the one hand, prevailing extracavity modulators such as liquid crystal spatial light modulator (LCSLM) and metasurface have emerged as powerful tools in tailoring spatial profiles of structured beams. However, they suffer from low damage threshold or low mode purity and are limited to nearfield application scenarios. Intra-cavity oscillations of structured light are envisaged to overcome these hurdles featuring high power/energy and high mode purity. However, scant attention is paid to constructing high-quality tunable laser source to realize them. Now, Yb:CALGO laser may stand up to be one of the perfect solution for the requirement of versatile tunable laser sources.

Author Contributions: H.W. and J.P. contribute equally to this work. H.W., J.P., Y.M., Q.L. and Y.S. contributed to data analysis and writing the manuscript, and this project is supervised by Q.L. and Y.S. All authors have read and agreed to the published version of the manuscript.

Funding: This research was funded by Key-Area Research and Development Program of Guangdong Province (2020B090922006); National Natural Science Foundation of China (NSFC) (61875100).

Data Availability Statement: Data underlying the results presented in this paper are not publicly available at this time but may be obtained from the authors upon reasonable request.

Acknowledgments: The authors thank Jiading Tian for useful discussions.

Conflicts of Interest: The authors declare no conflict of interest.

\section{References}

1. Hargrove, L.E.; Fork, R.L.; Pollack, M.A. Locking of He-Ne Laser Modes Induced by Synchronous Intracavity Modulation. Appl. Phys. Lett. 1964, 5, 4-5. [CrossRef]

2. McClung, F.J.; Hellwarth, R.W. Giant Optical Pulsations from Ruby. J. Appl. Phys. 1962, 33, 828-829. [CrossRef]

3. Strickland, D.; Mourou, G. Compression of amplified chirped optical pulses. Opt. Commun. 1985, 56, 219-221. [CrossRef]

4. Bloembergen, N. Nonlinear Optics; World Scientific: Singapore, 1996; p. 188.

5. Kawata, S.; Sun, H.-B.; Tanaka, T.; Takada, K. Finer features for functional microdevices. Nature 2001, 412, 697-698. [CrossRef] [PubMed]

6. Ma, Z.C.; Zhang, Y.L.; Han, B.; Hu, X.Y.; Li, C.H.; Chen, Q.D.; Sun, H.B. Femtosecond laser programmed artificial musculoskeletal systems. Nat. Commun. 2020, 11, 4536. [CrossRef] [PubMed]

7. Sugioka, K.; Cheng, Y. Ultrafast lasers-Reliable tools for advanced materials processing. Light Sci. Appl. 2014, 3, e149. [CrossRef]

8. Phillips, K.C.; Gandhi, H.H.; Mazur, E.; Sundaram, S.K. Ultrafast laser processing of materials: A review. Adv. Opt. Photonics 2015, 7, 684-712. [CrossRef]

9. Yun, S.H.; Kwok, S.J.J. Light in diagnosis, therapy and surgery. Nat. Biomed. Eng. 2017, 1, 0008. [CrossRef] 
10. Wang, Y.; Wang, S.; Zhu, Y.; Xu, H.; He, H. Molecular Response of Skin to Micromachining by Femtosecond Laser. Front. Phys. 2021, 9. [CrossRef]

11. Tso, F.; Byer, R. Modeling and CW operation of a quasi-three-level $946 \mathrm{~nm} \mathrm{Nd:} \mathrm{YAG} \mathrm{laser.} \mathrm{IEEE} \mathrm{J.} \mathrm{Quantum} \mathrm{Electron.} \mathrm{1987,} \mathrm{23,}$ 605-612. [CrossRef]

12. Cante, S.; Valle, S.; Yoon, S.J.; Mackenzie, J.I. 60-W 946-nm cryogenically-cooled Nd:YAG laser. Appl. Phys. B 2019, $125,135$. [CrossRef]

13. Wu, W.; Li, X.; Mei, F.; Chen, D.; Yan, R. 30 mJ, 1 kHz sub-nanosecond burst-mode Nd:YAG laser MOPA system. Opt. Express 2019, 27, 36129-36136. [CrossRef]

14. Davide Di Dio Cafiso, S.; Ugolotti, E.; Schmidt, A.; Petrov, V.; Griebner, U.; Agnesi, A.; Cho, W.B.; Jung, B.H.; Rotermund, F.; Bae, S.; et al. Sub-100-fs Cr:YAG laser mode-locked by monolayer graphene saturable absorber. Opt. Lett. 2013, 38, 1745-1747. [CrossRef]

15. Bae Cho, W.; Schmidt, A.; Young Choi, S.; Petrov, V.; Griebner, U.; Steinmeyer, G.; Lee, S.; Yeom, D.-I.; Rotermund, F. Mode locking of a Cr:YAG laser with carbon nanotubes. Opt. Lett. 2010, 35, 2669-2671. [CrossRef]

16. Chen, M.; Dai, S.; Yin, H.; Zhu, S.; Li, Z.; Chen, Z. Passively Q-switched yellow laser at 589 nm by intracavity frequency-doubled c-cut composite Nd:YVO4 self-Raman laser. Opt. Laser Technol. 2021, 133, 106534. [CrossRef]

17. Song, J.; Wang, Z.; Lv, R.; Wang, X.; Teng, H.; Zhu, J.; Wei, Z. Generation of 172 fs pulse from a Nd: YVO4 picosecond laser by using multi-pass-cell technique. Appl. Phys. B 2021, 127, 50. [CrossRef]

18. Petit, J.; Goldner, P.; Viana, B. Laser emission with low quantum defect in Yb:CaGdAlO4. Opt. Lett. 2005, 30, 1345-1347. [CrossRef]

19. Tan, W.D.; Tang, D.Y.; Xu, X.D.; Li, D.Z.; Zhang, J.; Xu, C.W.; Cong, Z.H.; Xu, J. Room temperature diode-pumped Yb:CaYAlO4 laser with near quantum limit slope efficiency. Laser Phys. Lett. 2011, 8, 193-196. [CrossRef]

20. Li, D.; Xu, X.; Cheng, Y.; Cheng, S.; Zhou, D.; Wu, F.; Xia, C.; Xu, J.; Zhang, J. Crystal growth and spectroscopic properties of $\mathrm{Yb}:$ CaYAlO4 single crystal. J. Cryst. Growth 2010, 312, 2117-2121. [CrossRef]

21. Kirkpatrick, S.M.; Druon, F.; Stoian, R.; Boudeile, J.; Zaouter, Y.; Hanna, M.; Balembois, F.; Georges, P.; Petit, J.; Golner, P.; et al. New Yb-doped crystals for high-power and ultrashort lasers. In Proceedings of the Femtosecond Phenomena and Nonlinear Optics III Conference, Stockholm, Sweden, 29 September 2006.

22. Descamps, D.; Guichard, F.; Petit, S.; Beauvarlet, S.; Comby, A.; Lavenu, L.; Zaouter, Y. High-power sub-15 fs nonlinear pulse compression at $515 \mathrm{~nm}$ of an ultrafast $\mathrm{Yb}$-doped fiber amplifier. Opt. Lett. 2021, 46, 1804-1807. [CrossRef]

23. Phillips, J.P.; Banerjee, S.; Mason, P.; Smith, J.; Spear, J.; De Vido, M.; Ertel, K.; Butcher, T.; Quinn, G.; Clarke, D.; et al. Second and third harmonic conversion of a kilowatt average power, 100-J-level diode pumped Yb:YAG laser in large aperture LBO. Opt. Lett. 2021, 46, 1808-1811. [CrossRef]

24. Deng, D.; Zhang, H.; Zu, J.; Chen, J. Buildup dynamics of a pulsating dissipative soliton in an all-normal-dispersion PM Yb-doped fiber laser with a NALM. Opt. Lett. 2021, 46, 1612-1615. [CrossRef]

25. Rosello-Mecho, X.; Delgado-Pinar, M.; Barmenkov, Y.O.; Kir'yanov, A.V.; Andres, M.V. Application of WGM Resonances to the Measurement of the Temperature Increment of Ho and Ho-Yb Doped Optical Fibers Pumped at 1125 and 975 nm. Sensors 2021, 21, 2094. [CrossRef]

26. Petit, J.; Viana, B.; Goldner, P. High thermal conductivity and low quantum defect in Yb:CaGdAlO4, a new infrared laser material for high power applications. In Proceedings of the Advanced Solid-State Photonics (TOPS), Vienna, Austria, 6-9 February $2005 ;$ p. 24.

27. Loiko, P.; Becker, P.; Bohaty, L.; Liebald, C.; Peltz, M.; Vernay, S.; Rytz, D.; Serres, J.M.; Mateos, X.; Wang, Y.; et al. Sellmeier equations, group velocity dispersion, and thermo-optic dispersion formulas for CaLnAlO4 ( $\mathrm{Ln}=\mathrm{Y}, \mathrm{Gd})$ laser host crystals. Opt. Lett. 2017, 42, 2275-2278. [CrossRef]

28. Di, J.Q.; Xu, X.D.; Xia, C.T.; Zheng, L.H.; Aka, G.; Yu, H.H.; Sai, Q.L.; Guo, X.Y.; Zhu, L. Crystal growth, polarized spectra, and laser performance of $\mathrm{Yb}: \mathrm{CaGdAlO4crystal.} \mathrm{Laser} \mathrm{Phys.} \mathrm{2016,} \mathrm{26,} \mathrm{045803.} \mathrm{[CrossRef]}$

29. Digonnet, M.J.F.; Jaffrès, A.; Ricaud, S.; Suganuma, A.; Viana, B.; Loiseau, P.; Georges, P.; Druon, F.; Jiang, S.; Dries, J.C. Yb: CALGO as material for high power ultrafast laser and focus on thermal conductivity variation. In Proceedings of the Optical Components and Materials X, San Francisco, CA, USA, 2-7 February 2013.

30. Verdùn, H.R.; Thomas, L.M. Growth, Optical Properties, and Stimulated Emission of Nd-Doped Aluminates with the K2NiF4 Structure. In Proceedings of the Advanced Solid State Lasers, Salt Lake City, UT, USA, 5-7 March 1990; p. MT4.

31. Petit, P.O.; Petit, J.; Goldner, P.; Viana, B. Inhomogeneous broadening of optical transitions in Yb:CaYAlO4. Opt. Mater. 2008, 30, 1093-1097. [CrossRef]

32. Lagatskii, A.A.; Kuleshov, N.V.; Shcherbitskii, V.G.; Kleptsyn, V.F.; Mikhailov, V.P.; Ostroumov, V.G.; Huber, G. Lasing characteristics of a diode-pumped Nd3+: CaGdAlO4crystal. Quantum Electron. 1997, 27, 15-17. [CrossRef]

33. Wentsch, K.S.; Weichelt, B.; Günster, S.; Druon, F.; Georges, P.; Ahmed, M.A.; Graf, T. Yb:CaF2 thin-disk laser. Opt. Express 2014, 22, 1524-1532. [CrossRef]

34. Petit, V.; Camy, P.; Doualan, J.L.; Portier, X.; Moncorgé, R. Spectroscopy ofYb3+:CaF2: From isolated centers to clusters. Phys. Rev. B 2008, 78, 085131. [CrossRef]

35. Druon, F.; Ricaud, S.; Papadopoulos, D.N.; Pellegrina, A.; Camy, P.; Doualan, J.L.; Moncorgé, R.; Courjaud, A.; Mottay, E.; Georges, P. On Yb:CaF2 and Yb:SrF2: Review of spectroscopic and thermal properties and their impact on femtosecond and high power laser performance [Invited]. Opt. Mater. Express 2011, 1, 489-502. [CrossRef]

36. Gao, Z.; Zhu, J.; Wang, J.; Wei, Z.; Xu, X.; Zheng, L.; Su, L.; Xu, J. Generation of 33 fs pulses directly from a Kerr-lens mode-locked Yb:CaYAlO_4 laser. Photonics Res. 2015, 3, 335-338. [CrossRef] 
37. Loiko, P.; Druon, F.; Georges, P.; Viana, B.; Yumashev, K. Thermo-optic characterization of Yb:CaGdAlO_4 laser crystal. Opt. Mater. Express 2014, 4, 2241-2249. [CrossRef]

38. Talik, E.; Kisielewski, J.; Zajdel, P.; Guzik, A.; Wierzbicka, E.; Kania, A.; Kusz, J.; Miga, S.; Szubka, M. XPS spectroscopy, structural, magnetic and dielectric investigations of $\mathrm{CaGdAlO} 4$ and $\mathrm{Yb}: \mathrm{CaGdAlO} 4$ single crystals. Opt. Mater. 2019, 91, 355-362. [CrossRef]

39. Druon, F.; Balembois, F.; Georges, P. New laser crystals for the generation of ultrashort pulses. C. R. Phys. 2007, 8, 153-164. [CrossRef]

40. Pirzio, F.; Kemnitzer, M.; Guandalini, A.; Kienle, F.; Veronesi, S.; Tonelli, M.; Aus der Au, J.; Agnesi, A. Ultrafast, solid-state oscillators based on broadband, multisite Yb-doped crystals. Opt. Express 2016, 24, 11782-11792. [CrossRef]

41. Loiko, P.; Serres, J.M.; Mateos, X.; Xu, X.; Xu, J.; Jambunathan, V.; Navratil, P.; Lucianetti, A.; Mocek, T.; Zhang, X.; et al. Microchip $\mathrm{Yb}$ :CaLnAlO4 lasers with up to 91\% slope efficiency. Opt. Lett. 2017, 42, 2431-2434. [CrossRef]

42. Brasselet, E.; Malinauskas, M.; Zukauskas, A.; Juodkazis, S. Photopolymerized microscopic vortex beam generators: Precise delivery of optical orbital angular momentum. Appl. Phys. Lett. 2010, 97, 211108. [CrossRef]

43. Beil, K.; Deppe, B.; Krankel, C. Yb:CaGdAlO4 thin-disk laser with 70\% slope efficiency and $90 \mathrm{~nm}$ wavelength tuning range. Opt. Lett. 2013, 38, 1966-1968. [CrossRef]

44. Sevillano, P.; Georges, P.; Druon, F.; Descamps, D.; Cormier, E. 32-fs Kerr-lens mode-locked Yb:CaGdAlO4 oscillator optically pumped by a bright fiber laser. Opt. Lett. 2014, 39, 6001-6004. [CrossRef]

45. Manjooran, S.; Major, A. Diode-pumped 45 fs Yb:CALGO laser oscillator with $1.7 \mathrm{MW}$ of peak power. Opt. Lett. 2018, 43, 2324-2327. [CrossRef]

46. Sroor, H.; Huang, Y.-W.; Sephton, B.; Naidoo, D.; Vallés, A.; Ginis, V.; Qiu, C.-W.; Ambrosio, A.; Capasso, F.; Forbes, A. High-purity orbital angular momentum states from a visible metasurface laser. Nat. Photonics 2020, 14, 498-503. [CrossRef]

47. Petit, J.; Goldner, P.; Viana, B.; Didierjean, J.; Balembois, F.; Druon, F.; Georges, P. Quest of athermal solid state laser: Case of $\mathrm{Yb}$ :CaGdAlO4. In Proceedings of the Photonics Europe, Strasbourg, France, 3-7 April 2006.

48. Li, D.Z.; Xu, X.D.; Cheng, S.S.; Zhou, D.H.; Wu, F.; Zhao, Z.W.; Xia, C.T.; Xu, J.; Zhang, J.; Zhu, H.M.; et al. Polarized spectral properties of Nd3+ ions in CaYAlO4 crystal. Appl. Phys. B 2010, 101, 199-205. [CrossRef]

49. Koerner, J.; Kaluza, M.C.; Kloepfel, D.; Vorholt, C.; Kahle, M.; Liebetrau, H.; Seifert, R.; Hein, J. Measurement of temperaturedependent absorption and emission spectra of Yb:YAG, Yb:LuAG, and Yb:CaF2 between $20{ }^{\circ} \mathrm{C}$ and $200{ }^{\circ} \mathrm{C}$ and predictions on their influence on laser performance. JOSA B 2012, 29, 2493-2502. [CrossRef]

50. Zaouter, Y.; Didierjean, J.; Balembois, F.; Leclin, G.L.; Druon, F.; Georges, P.; Petit, J.; Goldner, P.; Viana, B. 47-fs diode-pumped Yb3+:CaGdAlO4 laser. Opt. Lett. 2006, 31, 119-121. [CrossRef] [PubMed]

51. Caracciolo, E.; Kemnitzer, M.; Guandalini, A.; Pirzio, F.; Agnesi, A.; Aus der Au, J. High pulse energy multiwatt Yb:CaAlGdO4 and $\mathrm{Yb}: \mathrm{CaF} 2$ regenerative amplifiers. Opt. Express 2014, 22, 19912-19918. [CrossRef] [PubMed]

52. Boudeile, J.; Druon, F.; Hanna, M.; Georges, P.; Zaouter, Y.; Cormier, E.; Petit, J.; Goldner, P.; Viana, B. Continuous-wave and femtosecond laser operation of $\mathrm{Yb}: \mathrm{CaGdAlO} 4$ under high-power diode pumping. Opt. Lett. 2007, 32, 1962-1964. [CrossRef]

53. Wang, J.; Shi, L.; Li, Y.; Jin, L.; Xu, Y.; Zhang, H.; Zou, Y.; Lan, Y.; Ma, X. Thermal management of graphene-induced high-power semiconductor laser package with bidirectional conduction structure. Opt. Laser Technol. 2021, 139, 106927. [CrossRef]

54. Petit, J.; Viana, B.; Goldner, P.; Roger, J.-P.; Fournier, D. Thermomechanical properties of Yb3+ doped laser crystals: Experiments and modeling. J. Appl. Phys. 2010, 108, 123108. [CrossRef]

55. Jiang, S.; Digonnet, M.J.F.; Jaffres, A.; Sharma, S.K.; Loiseau, P.; Viana, B.; Doualan, J.L.; Moncorgé, R. UV-visible luminescence properties of the broad-band $\mathrm{Yb}: \mathrm{CALGO}$ laser crystal. In Proceedings of the Optical Components and Materials XII, San Francisco, CA, USA, 7-12 February 2015.

56. Akbari, R.; Loiko, P.; Major, A.; Clarkson, W.A.; Shori, R.K. Thermal lensing in diode-pumped Yb:CALGO and Yb:KGW lasers. In Proceedings of the Solid State Lasers XXIX: Technology and Devices, San Francisco, CA, USA, 4-6 February 2020.

57. Calendron, A.L. Dual-crystal Yb:CALGO high power laser and regenerative amplifier. Opt. Express 2013, $21,26174-26181$. [CrossRef]

58. Druon, F.; Olivier, M.; Jaffres, A.; Loiseau, P.; Aubry, N.; DidierJean, J.; Balembois, F.; Viana, B.; Georges, P. Magic mode switching in $\mathrm{Yb}: \mathrm{CaGdAlO} 4$ laser under high pump power. Opt. Lett. 2013, 38, 4138-4141. [CrossRef]

59. Hasse, K.; Calmano, T.; Deppe, B.; Liebald, C.; Krankel, C. Efficient Yb3+:CaGdAlO4 bulk and femtosecond-laser-written waveguide lasers. Opt. Lett. 2015, 40, 3552-3555. [CrossRef]

60. Hasse, K.; Kränkel, C. Yb:CALGO waveguide laser written with $1 \mathrm{MHz}$-repetition rate fs-laser. In Proceedings of the Laser Congress 2019 (ASSL, LAC, LS\&C), Vienna, Austria, 29 September-3 October 2019; p. ATu1A.7.

61. Manjooran, S.; Major, A.; Clarkson, W.A.; Shori, R.K. Comparative studies of high power diode-pumped Yb:CALGO and Yb:KYW lasers. In Proceedings of the Solid State Lasers XXVIII: Technology and Devices, San Francisco, CA, USA, 5-7 February 2019.

62. Reza, M.A.R.; Loiko, P.; Major, A.; Clarkson, W.A.; Shori, R.K. Intracavity loss measurement in a diode-pumped Yb:CALGO laser In Proceedings of the Solid State Lasers XXVIII: Technology and Devices, San Francisco, CA, USA, 5-7 February 2019.

63. Clarkson, W.A.; Ricaud, S.; Jaffres, A.; Loiseau, P.; Viana, B.; Weichelt, B.; Abdou-Ahmed, M.; Voss, A.; Graf, T.; Rytz, D.; et al. $\mathrm{Yb}: \mathrm{CaGdAlO} 4$ thin-disk. In Proceedings of the Solid State Lasers XXI: Technology and Devices, San Francisco, CA, USA, 22-25 January 2012.

64. Reza, A.R.; Akbari, R.; Major, A.; Clarkson, W.A.; Shori, R.K. Dual-wavelength Yb:CALGO laser with wavelength spacing tunability. In Proceedings of the Solid State Lasers XXIX: Technology and Devices, San Francisco, CA, USA, 4-6 February 2020. 
65. Ricaud, S.; Jaffres, A.; Loiseau, P.; Viana, B.; Weichelt, B.; Abdou-Ahmed, M.; Voss, A.; Graf, T.; Rytz, D.; Delaigue, M.; et al. $\mathrm{Yb}: \mathrm{CaGdAlO} 4$ thin-disk laser. Opt. Lett. 2011, 36, 4134-4136. [CrossRef]

66. Boudeile, J.; Didierjean, J.; Balembois, F.; Druon, F.; Georges, P.; Petit, J.; Goldner, P.; Viana, B. High power diode pumped $\mathrm{Yb3}+\mathrm{CaGdAlO} 4$ laser. In Proceedings of the Advanced Solid-State Photonics, Nara, Japan, 27-30 January $2008 ; \mathrm{p}$. WE28.

67. Scheller, M.; Yarborough, J.M.; Moloney, J.V.; Fallahi, M.; Koch, M.; Koch, S.W. Room temperature continuous wave milliwatt terahertz source. Opt. Express 2010, 18, 27112-27117. [CrossRef]

68. Chang, S.; Mao, Y.; Flueraru, C. Dual-Source Swept-Source Optical Coherence Tomography Reconstructed on Integrated Spectrum. Int. J. Opt. 2012, 2012, 565823. [CrossRef]

69. Manjooran, S.; Loiko, P.; Major, A. A discretely tunable dual-wavelength multi-watt Yb:CALGO laser. Appl. Phys. B 2017, 124, 13. [CrossRef]

70. Du, X.; Guo, J.; Wang, W.; Sun, D.; Gao, Y.; Liang, X. Wavelength shift with a diode-pumped continuous-wave Yb:CALGO laser. Appl. Opt. 2020, 59, 2097-2100. [CrossRef] [PubMed]

71. Forbes, A.; de Oliveira, M.; Dennis, M.R. Structured light. Nat. Photonics 2021, 15, 253-262. [CrossRef]

72. Forbes, A. Structured Light from Lasers. Laser Photonics Rev. 2019, 13, 1900140. [CrossRef]

73. Shen, Y.; Wang, X.; Xie, Z.; Min, C.; Fu, X.; Liu, Q.; Gong, M.; Yuan, X. Optical vortices 30 years on: OAM manipulation from topological charge to multiple singularities. Light Sci. Appl. 2019, 8, 90. [CrossRef]

74. Céspedes Vicente, O.; Caloz, C. Bessel beams: A unified and extended perspective. Optica 2021, 8, 451-457. [CrossRef]

75. Efremidis, N.K.; Chen, Z.; Segev, M.; Christodoulides, D.N. Airy beams and accelerating waves: An overview of recent advances Optica 2019, 6, 686. [CrossRef]

76. Wang, S.; Zhang, S.; Yang, H.; Xie, J.; Jiang, S.; Feng, G.; Zhou, S. Direct emission of chirality controllable femtosecond LG01 vortex beam. Appl. Phys. Lett. 2018, 112, 201110. [CrossRef]

77. Shen, Y.; Meng, Y.; Fu, X.; Gong, M. Wavelength-tunable Hermite-Gaussian modes and an orbital-angular-momentum-tunable vortex beam in a dual-off-axis pumped Yb:CALGO laser. Opt. Lett. 2018, 43, 291-294. [CrossRef]

78. Shen, Y.; Meng, Y.; Fu, X.; Gong, M. Dual-wavelength vortex beam with high stability in a diode-pumped Yb:CaGdAlO4laser. Laser Phys. Lett. 2018, 15, 055803. [CrossRef]

79. Bužek, V.; Quang, T. Generalized coherent state for bosonic realization of SU(2)Lie algebra. J. Opt. Soc. Am. B 1989, 6, 2447-2449. [CrossRef]

80. Shen, Y.; Wan, Z.; Fu, X.; Liu, Q.; Gong, M. Vortex lattices with transverse-mode-locking states switching in a large-aperture off-axis-pumped solid-state laser. J. Opt. Soc. Am. B 2018, 35, 2940-2944. [CrossRef]

81. Shen, Y.; Yang, X.; Fu, X.; Gong, M. Periodic-trajectory-controlled, coherent-state-phase-switched, and wavelength-tunable SU(2) geometric modes in a frequency-degenerate resonator. Appl. Opt. 2018, 57, 9543-9549. [CrossRef] [PubMed]

82. Shen, Y.; Wan, Z.; Meng, Y.; Fu, X.; Gong, M. Polygonal Vortex Beams. IEEE Photonics J. 2018, 10, 1-16. [CrossRef]

83. Pan, J.; Shen, Y.; Wan, Z.; Fu, X.; Zhang, H.; Liu, Q. Index-Tunable Structured-Light Beams from a Laser with an Intracavity Astigmatic Mode Converter. Phys. Rev. Appl. 2020, 14, 044048. [CrossRef]

84. Zhao, L.; Yuan, Y.; Tong, L.; Cai, F.; Zhang, W.; Cai, Y. Broadly tunable optical vortex beam in a diode-pumped Yb:CALGO laser. Opt. Laser Technol. 2021, 141, 107134. [CrossRef]

85. Wang, D.; Lei, M.; Lin, S.; Zheng, Y.; Kang, S.; Huang, L. Generation of a mode-tunable optical vortex based on a mirror curvature dynamically controlled Z-shaped resonant cavity. Opt. Lett. 2021, 46, 3079-3082. [CrossRef]

86. Yuan, Y.; Tong, L.; Cai, F.; Zhang, W.; Cai, Y.; Zhao, L. Direct generation of optical vortex arrays by rotating in an all-solid-state $\mathrm{Yb}$ :CALGO laser. Opt. Mater. Express 2021, 11, 1594-1602. [CrossRef]

87. Turpin, A.; Loiko, Y.V.; Kalkandjiev, T.K.; Mompart, J. Conical refraction: Fundamentals and applications. Laser Photonics Rev. 2016, 10, 750-771. [CrossRef]

88. Reza, A.R.; Akbari, R.; Fedorova, K.; Sokolovskii, G.; Rafailov, E.; Major, A.; Clarkson, W.A.; Shori, R.K. Diode-pumped $\mathrm{Yb}$ :CALGO laser with conical refraction output. In Proceedings of the Solid State Lasers XXIX: Technology and Devices, San Francisco, CA, USA, 4-6 February 2020.

89. Jiang, Y.; Yang, J.; Li, P.; Si, H.; Fu, X.; Liu, Q. High energy LiDAR source for long distance, high resolution range imaging. Microw. Opt. Technol. Lett. 2020, 62, 3655-3661. [CrossRef]

90. Edwards, M.J.; Patel, P.K.; Lindl, J.D.; Atherton, L.J.; Glenzer, S.H.; Haan, S.W.; Kilkenny, J.D.; Landen, O.L.; Moses, E.I.; Nikroo, A.; et al. Progress towards ignition on the National Ignition Facility. Phys. Plasmas 2013, 20, 070501. [CrossRef]

91. Malcolm, G.P.A.; Ferguson, A.I. Mode-locking of diode laser-pumped solid-state lasers. Opt. Quantum Electron. 1992, $24,705-717$. [CrossRef]

92. Agnesi, A.; Greborio, A.; Pirzio, F.; Reali, G.; Aus der Au, J.; Guandalini, A. 40-fs Yb3+:CaGdAlO4 laser pumped by a single-mode 350-mW laser diode. Opt. Express 2012, 20, 10077-10082. [CrossRef]

93. Alessandro, G.; Annalisa, G.; Juerg Aus der, A. Sub-100 fs pulses with 12.5-W from Yb:CALGO based oscillators. In Proceedings of the SPIE, San Francisco, CA, USA, 22-25 January 2012.

94. Agnesi, A.; Greborio, A.; Pirzio, F.; Ugolotti, E.; Reali, G.; Guandalini, A.; Aus der Au, J. Diode-pumped passively mode-locked tunable Yb:CALGO solid-state laser. J. Opt. Soc. Am. B 2013, 30, 1513-1516. [CrossRef]

95. Pirzio, F.; Cafiso, S.D.; Kemnitzer, M.; Guandalini, A.; Kienle, F.; Veronesi, S.; Tonelli, M.; Aus der Au, J.; Agnesi, A. Sub-50-fs widely tunable $\mathrm{Yb}: \mathrm{CaYAlO}(4)$ laser pumped by 400-mW single-mode fiber-coupled laser diode. Opt. Express 2015, 23, 9790-9795. [CrossRef] 
96. Mollenauer, L.F.; Stolen, R.H. The soliton laser. Opt. Lett. 1984, 9, 13-15. [CrossRef] [PubMed]

97. Phillips, C.R.; Mayer, A.S.; Klenner, A.; Keller, U. SESAM modelocked Yb:CaGdAlO4 laser in the soliton modelocking regime with positive intracavity dispersion. Opt. Express 2014, 22, 6060-6077. [CrossRef]

98. Phillips, C.R.; Mayer, A.S.; Klenner, A.; Keller, U. Femtosecond mode locking based on adiabatic excitation of quadratic solitons. Optica 2015, 2, 667-674. [CrossRef]

99. Mayer, A.S.; Phillips, C.R.; Keller, U. Watt-level 10-gigahertz solid-state laser enabled by self-defocusing nonlinearities in an aperiodically poled crystal. Nat. Commun. 2017, 8, 1673. [CrossRef] [PubMed]

100. Klenner, A.; Golling, M.; Keller, U. High peak power gigahertz Yb:CALGO laser. Opt. Express 2014, 22, 11884-11891. [CrossRef]

101. Kruger, L.M.; Mayer, A.S.; Okawachi, Y.; Ji, X.; Klenner, A.; Johnson, A.R.; Langrock, C.; Fejer, M.M.; Lipson, M.; Gaeta, A.L.; et al. Performance scaling of a 10-GHz solid-state laser enabling self-referenced CEO frequency detection without amplification. Opt. Express 2020, 28, 12755-12770. [CrossRef] [PubMed]

102. Liu, X.; Pang, M. Revealing the Buildup Dynamics of Harmonic Mode-Locking States in Ultrafast Lasers. Laser Photonics Rev. 2019, 13, 1800333. [CrossRef]

103. Bensch, H.M.; Herink, G.; Kurtz, F.; Morgner, U. Harmonically mode-locked Yb:CALGO laser oscillator. Opt. Express 2017, 25, 14164-14172. [CrossRef]

104. Wang, S.; Wang, Y.B.; Feng, G.Y.; Zhou, S.H. Harmonically mode-locked Yb:CALGO laser pumped by a single-mode $1.2 \mathrm{~W}$ laser diode. Opt. Express 2018, 26, 1521-1529. [CrossRef]

105. Gao, Z.; Zhu, J.; Wang, J.; Wang, Z.; Wei, Z.; Xu, X.; Zheng, L.; Su, L.; Xu, J. Diode-pumped Kerr-lens mode-locked $\mathrm{Yb}:$ CaGdAlO4laser with tunable wavelength. Laser Phys. Lett. 2016, 13, 015302. [CrossRef]

106. Papadopoulos, D.N.; Druon, F.; Boudeile, J.; Martial, I.; Hanna, M.; Georges, P.; Petit, P.O.; Goldner, P.; Viana, B. Low-repetitionrate femtosecond operation in extended-cavity mode-locked Yb:CALGO laser. Opt. Lett. 2009, 34, 196-198. [CrossRef] [PubMed]

107. Shori, R.K.; Clarkson, W.A.; Major, A.; Manjooran, S. Low repetition rate operation of a femtosecond Yb:CALGO laser. In Proceedings of the Solid State Lasers XXVII: Technology and Devices, San Francisco, CA, USA, 29 January-1 February 2018.

108. Kimura, S.; Tani, S.; Kobayashi, Y. Raman-assisted broadband mode-locked laser. Sci. Rep. 2019, 9, 3738. [CrossRef]

109. Labaye, F.; Wittwer, V.J.; Modsching, N.; Razskazovskaya, O.; Cormier, E.; Südmeyer, T. Yb.CALGO Oscillator Generates 31-fs Pulses with $389 \mathrm{~mW}$ at 29\% Efficiency by Cross-Polarized Optical Pumping. In Proceedings of the Conference on Lasers and Electro-Optics, Washington, DC, USA, 10-15 May 2020; p. SF2H.2.

110. Wang, Y.; Su, X.; Xie, Y.; Gao, F.; Kumar, S.; Wang, Q.; Liu, C.; Zhang, B.; Zhang, B.; He, J. 17.8 fs broadband Kerr-lens mode-locked $\mathrm{Yb}:$ CALGO oscillator. Opt. Lett. 2021, 46, 1892-1895. [CrossRef]

111. Klenner, A.; Keller, U. All-optical Q-switching limiter for high-power gigahertz modelocked diode-pumped solid-state lasers. Opt. Express 2015, 23, 8532-8544. [CrossRef] [PubMed]

112. Wang, Y.; Wang, S.; Feng, G.; Zhou, S. SESAM combined Kerr lens mode locked Yb:CALGO laser pumped by a 1.2 W single mode fiber coupled laser diode. Laser Phys. Lett. 2017, 14, 055003. [CrossRef]

113. Akbari, R.; Zhao, H.; Fedorova, K.A.; Rafailov, E.U.; Major, A. Quantum-dot saturable absorber and Kerr-lens mode-locked $\mathrm{Yb}: \mathrm{KGW}$ laser with $>450 \mathrm{~kW}$ of peak power. Opt. Lett. 2016, 41, 3771-3774. [CrossRef] [PubMed]

114. Tong, L.; Cai, F.; Xu, Q.; Ji, Y.; Liu, J.; Cai, Y.; Zhao, L. Nonlinear-mirror mode-locked 1052 nm Yb:CALGO laser. Opt. Quantum Electron. 2019, 51, 223. [CrossRef]

115. Caracciolo, E.; Kemnitzer, M.; Guandalini, A.; Pirzio, F.; Aus der Au, J.; Agnesi, A. 28-W, 217 fs solid-state Yb:CAlGdO4 regenerative amplifiers. Opt. Lett. 2013, 38, 4131-4133. [CrossRef]

116. Pouysegur, J.; Delaigue, M.; Zaouter, Y.; Honninger, C.; Mottay, E.; Jaffres, A.; Loiseau, P.; Viana, B.; Georges, P.; Druon, F. Sub-100-fs Yb:CALGO nonlinear regenerative amplifier. Opt. Lett. 2013, 38, 5180-5183. [CrossRef]

117. Caracciolo, E.; Kemnitzer, M.; Rumpel, M.; Guandalini, A.; Pirzio, F.; Kienle, F.; Graf, T.; Abdou Ahmed, M.; Aus der Au, J.; Agnesi, A. Single-grating-mirror intracavity stretcher design for chirped pulse regenerative amplification. Opt. Lett. 2015, 40, 1532-1535. [CrossRef]

118. Molteni, L.M.; Canella, F.; Pirzio, F.; Betz, M.; Vicentini, E.; Coluccelli, N.; Piccinno, G.; Agnesi, A.; Laporta, P.; Galzerano, G. Low-noise Yb:CALGO optical frequency comb. Opt. Express 2021, 29, 19495-19505. [CrossRef]

119. Wang, W.; Wu, H.; Liu, C.; Sun, B.; Liang, H. Multigigawatt 50fs Yb:CALGO regenerative amplifier system with $11 W$ average power and mid-infrared generation. Photonics Res. 2021, 9, 1439-1445. [CrossRef]

120. Ricaud, S.; Jaffres, A.; Wentsch, K.; Suganuma, A.; Viana, B.; Loiseau, P.; Weichelt, B.; Abdou-Ahmed, M.; Voss, A.; Graf, T.; et al. Femtosecond $\mathrm{Yb}: \mathrm{CaGdAlO} 4$ thin-disk oscillator. Opt. Lett. 2012, 37, 3984-3986. [CrossRef] [PubMed]

121. Diebold, A.; Emaury, F.; Schriber, C.; Golling, M.; Saraceno, C.J.; Sudmeyer, T.; Keller, U. SESAM mode-locked Yb:CaGdAlO4 thin disk laser with 62 fs pulse generation. Opt. Lett. 2013, 38, 3842-3845. [CrossRef] [PubMed]

122. Modsching, N.; Paradis, C.; Labaye, F.; Gaponenko, M.; Graumann, I.J.; Diebold, A.; Emaury, F.; Wittwer, V.J.; Sudmeyer, T. Kerr lens mode-locked Yb:CALGO thin-disk laser. Opt. Lett. 2018, 43, 879-882. [CrossRef] [PubMed] 